\title{
Ortoneises en la Franja Silos-Babega, Macizo de Santander, Colombia: evidencias de la orogenia famatiniana en los Andes del norte
}

\author{
Carlos Alberto García-Ramírez ${ }^{1}$, Vanessa Rey-León ${ }^{1}$, Víctor Valencia $^{2}$
}

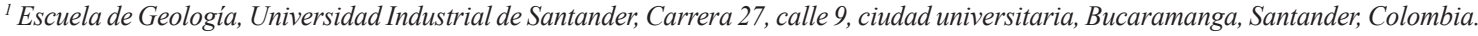 \\ cgarciar@uis.edu.co; vannerey0722@hotmail.com \\ ${ }^{2}$ School of the Environment, Washington State University, Pullman, Washington State 99163, United States of America. \\ vicvalencia1@gmail.com
}

\begin{abstract}
RESUMEN. La Unidad Ortoneis presente en el Macizo de Santander, ubicado en los Andes del Norte de Colombia, está compuesta principalmente de ortoneises cuarzo-feldespáticos, pelíticos y en menor proporción ortoneises de composición máfica y anfibolitas. Estudios petrográficos, geoquímicos y geocronológicos realizados en ortoneises de la franja SilosBabega indican que son de composición granodiorítica y granítica con protolito formado a partir de fusión parcial de corteza en ambientes de arco continental activo. Los protolitos de estos ortoneises se emplazaron de forma sintectónica en rocas de la unidad Esquistos del Silgará. El metamorfismo de la Unidad Ortoneis alcanzó condiciones de la facies anfibolita, con presiones y temperaturas en el rango $4,3-10 \mathrm{~Kb}$ y $540-690^{\circ} \mathrm{C}$, respectivamente. Edades U-Pb LA-ICP-MS en circones de 471 y 479 Ma son similares a las obtenidas en los sectores central y nororiental del Macizo de Santander y confirman la continuidad del protomargen andino como resultado de la orogenia Famatiniana.
\end{abstract}

Palabras clave: Macizo de Santander, Andes colombianos, Ortoneis, Orogenia Famatiniana.

\begin{abstract}
Orthogneisses from the Silos-Babega strip, Santander Massif, Colombia: evidences of famatinian orogeny in the north andes. The Orthogneiss unit in the Santander Massif, Northern Colombian Andes, mainly consists of quartzfeldspathic, pelitic and minor mafic orthogneisses and amphibolites. Petrographic, geochemical and geochronological studies carried out on orthogneisses from the Silos-Babega belt, indicate that they are granodioritic and granitic in composition with protolith formed by crustal melting in an active continental magmatic arc. They were syntectonically emplaced in the Silgara Schists unit. Metamorphic peak of the Orthogneiss unit reach amphibolite facies conditions in the range of 4.3-10 kbar in pressure and 540-690 ${ }^{\circ} \mathrm{C}$ in temperature. Zircon U-Pb LA-ICP-MS ages of $471 \pm 11$ and $479 \pm 10 \mathrm{Ma}$ were obtained and these ages are similar to those known for the Orthogneiss unit in the central and the eastern Santander Massif and confirm the continuity to the north of the Andean protomargin as a result of the Famatinian orogeny.
\end{abstract}




\section{Introducción}

Los ortoneises de edad ordovícica del presente estudio afloran en los sectores central, NE y SW del Macizo de Santander, Cordillera Oriental de los Andes colombianos. Estos ortoneises fueron agrupados por Ward et al. (1973) en la unidad Ortoneis, definiendo al menos dos tipos de ortoneises: 1 . cuerpos pequeños de posible edad precámbrica, asociados al Neis de Bucaramanga; 2. cuerpos mayores de amplia distribución, asociados en contacto intrusivo a las unidades Neis de Bucaramanga y Esquistos del Silgará. En este estudio presentamos las características petrográficas, geoquímicas y geocronológicas del segundo tipo de ortoneis. Estos ortoneises ocurren como franjas alargadas en dirección N-S o como masas irregulares bordeando las rocas del Neis de Bucaramanga y Esquistos del Silgará. Las rocas de la unidad Ortoneis comprenden neises pelíticos, cuarzo-feldespáticos y máficos, y cuerpos discontinuos de anfibolitas foliadas de forma lenticular y tabular. Las foliaciones de los neises y anfibolitas son siempre concordantes.

\section{Marco Geológico}

El Macizo de Santander (MS) es la continuación norte de la Cordillera Oriental de los Andes de Colombia y forma la margen S-E del bloque triangular de Maracaibo. Hacia el norte de Bucaramanga esta margen occidental está bien definida por el sistema de fallas Bucaramanga-Santa Marta a lo largo de una dirección NNW (Van der Lelij et al., 2015) y hacia el límite este, se encuentra definida por el sistema de fallas Pamplona-Cubogón-Mercedes. (García et al., 2005) (Fig.1). El MS forma parte por tanto de los Andes del Norte según Gansser (1973), y Alemán y Ramos (2000). El carácter autóctono, para-autóctono y alóctono del MS es aún motivo de debate (Toussaint y Restrepo, 1988; Cediel et al., 2003; Restrepo-Pace y Cediel, 2010; Van der Lelij et al., 2015).

El basamento metamórfico del MS consiste en las siguientes unidades litológicas: Neis de Bucaramanga, Esquistos del Silgará (s.s.), Esquistos del Chicamocha (nombre temporal asignado a esquistos y cuarcitas, aflorantes al SW del MS en los sectores PescaderoAratoca), Ortoneis, y Filitas de San Pedro (Ward et al., 1973; Royero y Clavijo, 2001; Mantilla et al., 2016a). Otros autores mencionan también las Metasedimentitas de Guaca (Royero y Clavijo, 2001). Estas unidades están cubiertas por rocas sedimentarias del Devónico
(Boinet et al., 1985) (Figs. 1 y 2). A continuación, se describen brevemente estas unidades.

\subsection{Neis de Bucaramanga}

Las rocas del Neis de Bucaramanga son neises pelíticos (neis biotítico, neis biotítico con sillimanita y granate) y máficos (neis hornbléndico), cuarcitas sillimaníticas y granatíferas, mármoles, anfibolitas y migmatitas. El grado metamórfico de esta unidad corresponde a la zona de la sillimanita en facies anfibolita. El protolito de esta unidad se ha considerado Meso-Proterozoico, siendo el evento metamórfico de edad $1020 \mathrm{Ma}$ (Cordani et al., 2005).

\subsection{Esquistos de Silgará (s.s.)}

Esta unidad fue definida como Formación Silgará (Ward et al., 1973) en una sección expuesta en la quebrada Silgará, al NW del Macizo de Santander. Esta formación también aflora en los sectores central y nororiental del MS como franjas alargadas con dirección NS. En zonas cercanas a la sección tipo, esta unidad es de bajo a medio grado de metamorfismo (zona del granate en facies esquistos verdes) y consta de metaareniscas, cuarcitas, metagrauvacas, esquistos micáceos, esquistos micáceos con granate y filitas cloríticas. En los sectores central y NE el grado de metamorfismo es mayor (zona de la sillimanita, facies anfibolita) y las rocas son esquistos micáceos, esquistos granatíferos con estaurolita \pm cianita \pm sillima-nita, cuarcitas moscovíticas, granatíferas y mármoles (García et al., 2005; Castellanos et al., 2008). Estudios recientes (Mantilla et al., 2016a; Cardona et al., 2016) muestran que la complejidad litológica y de facies de esta unidad también se relaciona con su edad de depositación y de metamorfismo. Mantilla et al. (2016a) y Mantilla et al. (2016b) basados en edades U-Pb y Lu-Hf en circones han propuesto dividir esta unidad en Esquistos del Silgará, Esquistos del Chicamocha y Filitas de San Pedro. Esta nomenclatura se acoge en el presente trabajo.

\subsection{Esquistos de Chicamocha}

La unidad Esquistos del Chicamocha es una sucesión de cuarcitas y metapelitas: esquistos micáceos con granate, estaurolita, cianita/andalucita y sillimanita, y metabasitas (esquistos anfibólicos y anfibolitas). Esta secuencia aflora al SW del MS en el cañón del río Chicamocha y por la vía entre los 
Municipios de Piedecuesta y Aratoca. La edad máxima de depositación de esta unidad es del Cámbrico Medio ( 500 Ma; Mantilla et al., 2016a). El metamorfismo es de alto grado, alcanzando la zona de la sillimanita en facies anfibolita (Ríos et al., 2003).

\subsection{Filitas de San Pedro}

Las Filitas de San Pedro se consideraba como parte constituyente de la Formación Silgará; sin embargo, edades U-Pb en circones detríticos (Mantilla et al., 2016a) muestran que su máxima edad de depositación es Ordovícico Tardío ( 450 Ma). Litológicamente consta de filitas cloríticas y meta-areniscas. La edad del metamorfismo aún no ha sido determinada con certeza. Mantilla et al. (2016a), sobre la base de relaciones de campo y las edades registradas para rocas sin metamorfismo del MS, proponen una edad del Ordovícico Tardío.

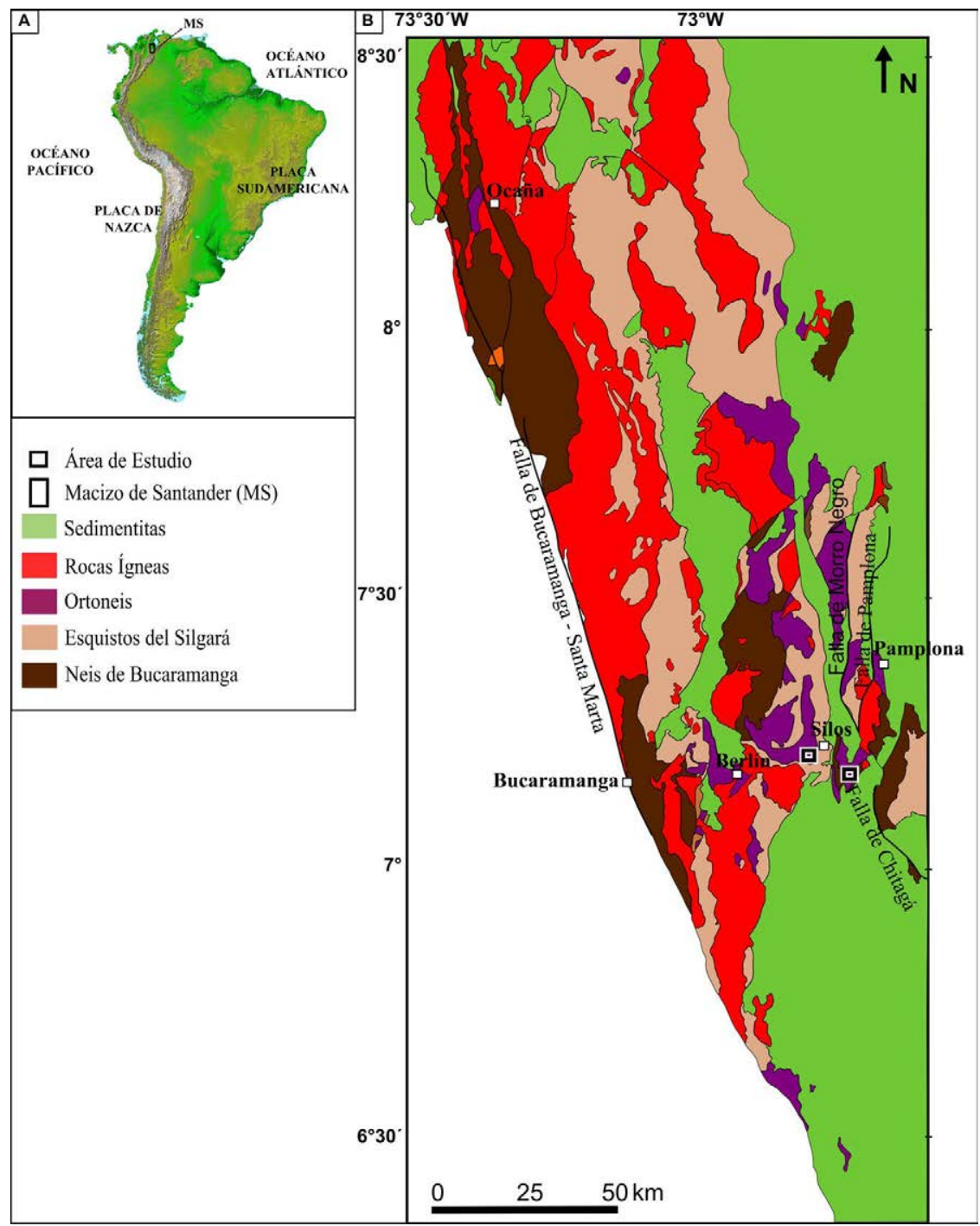

FIG 1. Localización del Macizo de Santander. A. Mapa de Suramérica que muestra el sistema andino. Tomado de http://www2.jpl. nasa.gov $/^{1}$. B. Esquema geológico del Macizo de Santander que muestra la distribución de la unidad Ortoneis y las zonas de estudio (en rectángulos).

${ }^{1}$ Imagen de la Nasa. Recuperado de http://www2.jpl.nasa.gov/ (última visita 07/03/2017). 


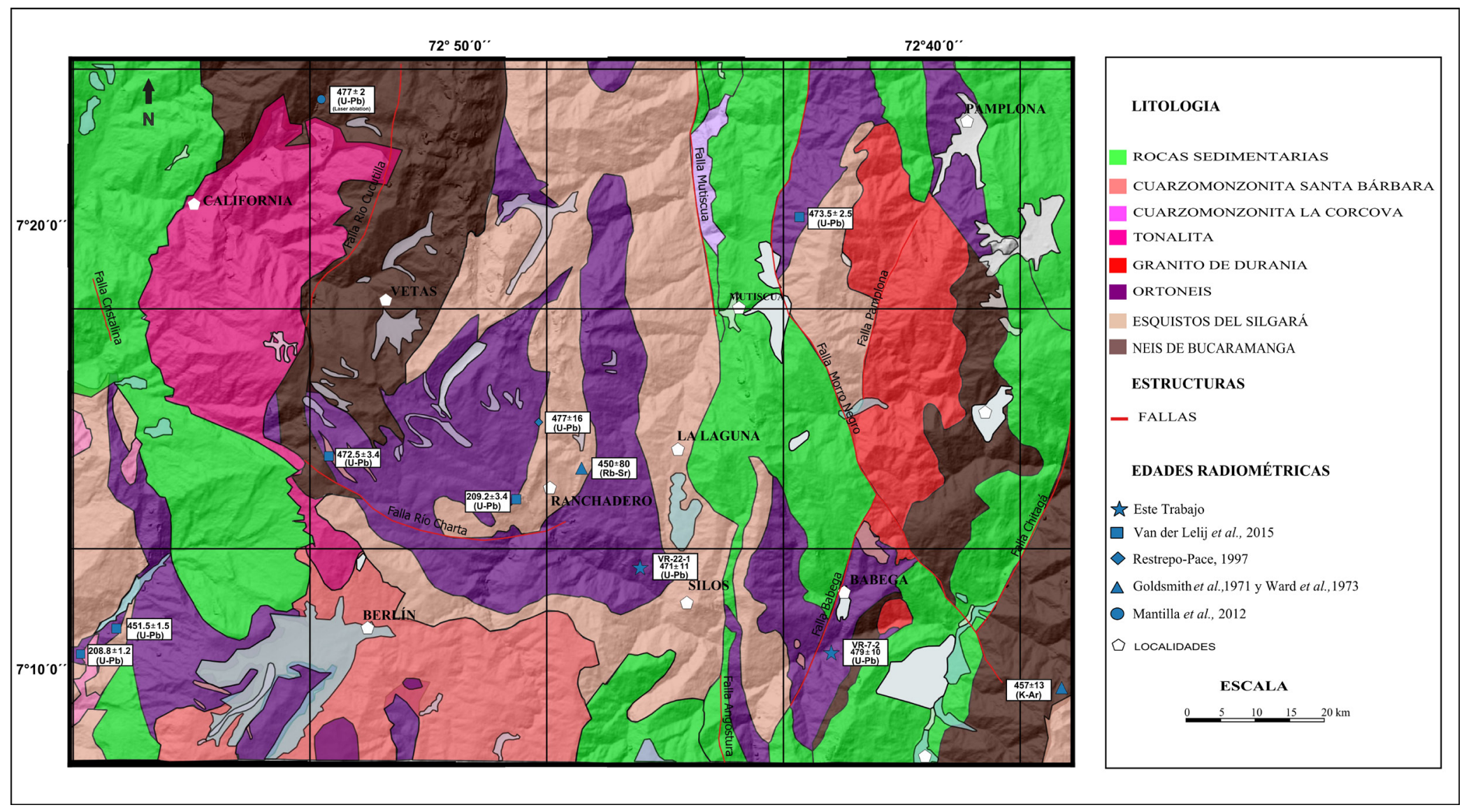

FIG 2. Mapa geológico del área de estudio que indica la ubicación de las muestras analizadas. 


\subsection{Ortoneis}

Los cuerpos más grandes de esta unidad se localizan en los sectores central y NE del MS. Esta unidad consta de neises cuarzo-feldespáticos, biotíticos $\mathrm{y}$, en menor proporción neises hornbléndicos y algunos cuerpos lenticulares de anfibolitas. El protolito de estas rocas se emplazó de forma sintectónica durante el Ordovícico Temprano y posiblemente tardío (evento Famatiniano Principal) en torno a 480-472 Ma (Restrepo-Pace y Cediel, 2010; Mantilla et al., 2012; Van der Lelij, 2013). Otros cuerpos de Ortoneis se encuentran asociados a rocas del Neis de Bucaramanga (Ward et al., 1973). Las rocas del Ortoneis cortan la unidad Neis de Bucaramanga e intruyen de forma sintectónica los Esquistos de Silgará, las foliaciones de ambas unidades son concordantes. Por otra parte, se ha señalado que en el sector central del MS, granitos sintectónicos (protolito del Ortoneis) se emplazaron en los Esquistos de Silgará cuando esta unidad alcanzó el pico metamórfico (García et al., 2005; Castellanos et al., 2008).

Esta unidad es el objetivo central del presente trabajo, por lo cual se tratará en detalle más adelante.

\section{Estudios Anteriores}

Ward et al. (1973) y Royero y Clavijo (2001) realizaron estudios cartográficos de las rocas del Ortoneis a lo largo del MS. Según Ward et al. (1973) la mayor parte del Ortoneis aflora en el sector norte del área cartografiada en el cuadrángulo $\mathrm{H}-13$ al suroeste, norte y noreste de Berlín, existiendo cuñas angostas de ortoneis que se extienden al sur hasta Chitagá y Silos y que afloran en franjas falladas en una faja hacia el oeste de Pamplona (Fig. 1). Otro cuerpo de Ortoneis aflora a lo largo del borde oriental de los batolitos de Santa Bárbara y Mogotes, hasta el extremo sur de los alrededores de Onzaga. Por otro lado, Royero y Clavijo (2001) proponen el nombre de Ortoneis de Berlín a los neises aflorantes en los alrededores de Berlín, donde tiene su mayor extensión y está mejor expuesto (carretera BucaramangaPamplona). El Ortoneis de Berlín intruye al Neis de Bucaramanga y está cubierto discordantemente por sedimentitas del Devónico Medio.

Estudios petrográficos y geoquímicos indican que la composición de las rocas del Ortoneis comprende rocas pelíticas (neises biotíticos), máficas (neises biotítico-hornbléndico o con hornblenda) y rocas félsicas (neises cuarzo-feldespáticos) de afinidad calcoalcalina, emplazadas en ambientes sincolisionales (García et al., 2005; Castellanos et al., 2008; Rey y García, 2015).

Goldsmith et al. (1971) obtuvieron las siguientes edades para el Ortoneis: $413 \pm 30$ Ma en una metadiorita mediante el método K-Ar en hornblenda; $457 \pm 13 \mathrm{Ma}$ en pegmatita del Neis de Bucaramanga usando el método K-Ar en muscovita y $450 \pm 80 \mathrm{Ma}$ en un granito neísico, método R-Sr en roca total. Esto sugiere un evento magmático a finales del Ordovícico o principios del Silúrico.

Ward et al. (1973) mediante el método $\mathrm{Rb} / \mathrm{Sr}$ en roca total obtuvieron una edad de $450 \pm 80 \mathrm{Ma}$ en un Ortoneis en el río Caraba, sector de Berlín. Forero, 1990 reporta dataciones radiométricas basadas en el método de $\mathrm{K}-\mathrm{Ar}$ en roca total, obteniendo una edad entre los 465 a $421 \mathrm{Ma}$, lo que la ubicaría en el Ordovícico Medio a Tardío-Devónico Temprano.

Una edad U-Pb en circón de $477 \pm 16 \mathrm{Ma}$, obtenida por Restrepo-Pace (1995) al NE de Berlín por la vía Berlín-Pamplona, en un cuerpo de Ortoneis, sugiere una edad del Ordovícico Inferior para esta unidad.

En el sector de California, sector NW del MS, afloran dioritas foliadas, con evidencia de metamorfismo regional con edades $\mathrm{U}-\mathrm{Pb}$ en circones en torno a $477 \pm 2 \mathrm{Ma}$ (Mantilla et al., 2012).

Van Der Lelij (2013) reportó edades U-Pb en circones entre 451 y 473 Ma para el Ortoneis que aflora por la carretera Berlín-Pamplona. Las edades $\mathrm{Ar} / \mathrm{Ar}$ en micas y hornblenda de 194-210 Ma en los mismos ortoneises indican un evento termal relacionado con el emplazamiento de un cinturón magmático del JurásicoTriásico, evento ampliamente registrado en el MS.

Las condiciones P-T de metamorfismo para las rocas de la parte central del MS, en la que afloran numerosos cuerpos de Ortoneis sintectónicos definidas por García et al. (2005), indican un metamorfismo barroviense, en el que se desarrollaron las zonas: estaurolita-cianita, sillimanita baja y sillimanita alta, acompañada de migmatización. Las condiciones de presión y temperatura, estimadas mediante el programa TWQ, están en el rango de 5,0-9,5 kbar y 630-727 ${ }^{\circ} \mathrm{C}$. La trayectoria PT obtenida es en sentido horario evidenciando un ambiente de colisión para esta región de los Andes colombianos.

\section{Metodologia}

Durante una fase inicial de campo en rocas de la unidad Ortoneis, se recolectaron datos geológicos 
relacionados con su ocurrencia, relación con las litologías encajantes o asociadas, características meso y macroestructurales, así como los aspectos mineralógicos y texturales. Se muestrearon diferentes variedades litológicas para los estudios petrográficos, geoquímicos y geocronológicos.

Los estudios petrográficos se realizaron en el laboratorio de Petrografía de la Escuela de Geología de la Universidad Industrial de Santander, usando un microscopio triocular marca Leica, modelo DM750POL. Las abreviaturas minerales usadas son las de Whitney y Evans (2010). Los análisis geoquímicos se realizaron en el laboratorio ALS Laboratories en Vancouver, Canadá. Las condiciones del análisis fueron las siguientes: $250 \mathrm{~g}$ de roca fueron trituradas y pulverizadas y se tomó la fracción $<$ a mallas 200 . El contenido de $\mathrm{FeO}$ fue determinado por titulación. Los elementos mayores y menores fueron analizados por fluorescencia de rayos X (XRF). Elementos traza $\mathrm{y}$ tierras raras fueron analizados mediante ICP-MS. Los límites de detección de elementos mayores son de $0,01 \%$, elementos traza y tierras raras de 0,5 y $0,1 \mathrm{ppm}$ respectivamente. Se realizó por duplicado análisis de la muestra VR-7-2 arrojando error entre 0 y $1,02 \%$. Adicional a esto, el laboratorio reporta los valores de los estándares NCSDC73303 y SRM88B, así como la muestra blanco usada. Los valores reportados (muestras analizadas, duplicado, estándares y blanco) son todos certificados por ALS Laboratorios. Los datos geoquímicos fueron procesados mediante el programa de libre acceso Geochemical Data Toolkit (GCDKit) versión 4.1 (Janousek et al., 2006), disponible en la página web: http://www.gcdkit.org/ (última visita 15/02/2017).

La metodología para las dataciones $\mathrm{U}-\mathrm{Pb}$ en circones fue la siguiente: las muestras de ortoneis fueron trituradas, pulverizadas, separadas gravimétricamente y tamizadas. El concentrado de minerales pesados de la fracción $<350$ micrones fue procesado, usando técnicas tradicionales (separación paramagnética y líquidos pesados) para la separación de circones, en el laboratorio ZirChron LLC en Tucson AZ (http:// www.zirchron.com) (última visita 18/11/2016).

Circones de la fracción no magnética y estándares fueron seleccionados a mano evitando circones con fracturas e inclusiones visibles. Los estándares Plesovice y FC1 fueron montados junto con las muestras en resina epóxica en un anillo fenólico de una pulgada. Posteriormente el montaje fue ligeramente desbastado y pulido para exponer la superficie de los circones y mantener la mayor cantidad de material para los análisis por ablación láser. Posterior a la toma de imágenes de catodoluminiscencia en la Universidad de Idaho, los análisis de U-Pb en circón por espectrometría de masas por ablación láser (LAICPMS U-Pb) se llevaron a cabo en la Universidad del Estado de Washington usando un sistema láser New Wave Nd:YAG UV 213-nm láser, acoplado a un espectrómetro ThermoFinnigan Element 2, con colector único, doble foco y sector magnético. Parámetros y procedimientos de operación son similares a los reportados en Chang et al. (2006). Las condiciones del láser fueron un diámetro de 30 micrones y una repetición de $10 \mathrm{~Hz}$. Una mezcla de He y Ar se usaron como gas para transportar el aerosol de la muestra al plasma. Cada análisis consistió de un análisis de blanco seguido por 250 barridas de las masas 202, 204, 206, 207, 208, 232, 235 y 238 , lo cual toma alrededor de 30 segundos. La fraccionación independiente del tiempo fue corregida normalizando las razones de $\mathrm{U} / \mathrm{Pb}$ and $\mathrm{Pb} / \mathrm{Pb}$ de los circones desconocidos a las de los circones estándares (Chang et al., 2006). La concentración de $\mathrm{U}$ y Th fueron monitoreadas por comparación de vidrio estándar de tierras raras NIST 610. Se utilizaron dos estándares de circones: Plesovice con una edad de 338 Ma (Sláma et al., 2008) y FC-1, con una edad de 1099 Ma (Paces and Miller, 1993). Las edades y diagramas fueron calculados usando Isoplot (Ludwig, 2003). Errores de las edades fueron calculados siguiendo Valencia et al. (2005). La mejor edad (Best age cut-off) reportada corresponde a la edad ${ }^{206} \mathrm{~Pb} /{ }^{238} \mathrm{U}$ para edades más jóvenes a $1000 \mathrm{Ma}$, y la edad ${ }^{206} \mathrm{~Pb} /{ }^{207} \mathrm{~Pb}$ para edades más antiguas a $1000 \mathrm{Ma}$.

Los resultados de los datos analíticos se presentan en el apéndice 2. Las incertidumbres mostradas en estas tablas son a nivel de 1 sigma, e incluyen solamente los errores medidos. Para cada análisis, generalmente los errores en determinar la razón ${ }^{206} \mathrm{~Pb} / 238 \mathrm{U}$ resultan en un error medido de $\sim 1-3 \%$ en la edad ${ }^{206} \mathrm{~Pb} /{ }^{238} \mathrm{U}$. Los errores en la medición de la razón ${ }^{207} \mathrm{~Pb} /{ }^{206} \mathrm{~Pb}$ también resulta en una incertidumbre de $\sim 1 \%$ en la edad ${ }^{206} \mathrm{~Pb} /{ }^{207} \mathrm{~Pb}$ para circones con edades mayores a $1000 \mathrm{Ma}$, pero es mayor en granos más jóvenes debido a una menor intensidad en la señal del ${ }^{207} \mathrm{~Pb}$. La mejor edad (Best Age) corresponde a la edad ${ }^{206} \mathrm{~Pb} /{ }^{238} \mathrm{U}$ para circones $<1000 \mathrm{Ma}$ y la edad ${ }^{207} \mathrm{~Pb} /{ }^{206} \mathrm{~Pb}$ es utilizada para circones $>1000$ Ma. Esta división resulta del incremento de la incertidumbre de la edad ${ }^{206} \mathrm{~Pb} /{ }^{238} \mathrm{U}$ y la disminución 
de la incertidumbre de la edad ${ }^{207} \mathrm{~Pb} /{ }^{206} \mathrm{~Pb}$ en función del incremento de la edad a partir de $1000 \mathrm{Ma}$.

Las edades de los ortoneises fueron calculadas utilizando la subrutina de zircón age extractor (TuffZirc age) para extraer edades y errores coherentes de un grupo de edades ${ }^{206} \mathrm{~Pb} /{ }^{238} \mathrm{U}$, a partir de una población compleja de circones. Este algoritmo fue elaborado para minimizar los efectos de herencia y pérdida de plomo sobre las edades obtenidas a partir del análisis de poblaciones de circones (Ludwig and Mundil, 2002). Estos diagramas fueron calculados con edad e incertidumbre de los errores medidos solamente. La edad final fue calculada usando las dos incertidumbres: la primera derivada del cálculo del grupo de edades por TUFFZIRC y la segunda representa el error sistemático (incertidumbre de estándar, calibracion del estándar y constantes de decaimiento) que para esta sesión fue de $1,9 \%$ para la edad ${ }^{206} \mathrm{~Pb} /{ }^{238} \mathrm{U}$ y $0,9 \%$ para la edad ${ }^{207} \mathrm{~Pb} /{ }^{206} \mathrm{~Pb}$. La incertidumbre total de la edad es determinada como la suma cuadrática de ambos errores para el grupo de análisis; en este caso los errores son asimétricos y varían de $\sim 2,0-2,4 \%(2 \sigma)$.

\section{Petrografía}

Las rocas de la unidad Ortoneis presentes en la zona de estudio constituyen principalmente cuerpos alargados en dirección N-S y cuerpos que se disponen en masas. Litológicamente, el Ortoneis consta de neises pelíticos (neis moscovítico, neis biotítico, neis biotítico con sillimanita y neis biotítico con hornblenda y magnetita), máficos (neis hornbléndico), y neises cuarzo-feldespáticos (neis cuarzo-feldespático con biotita y neis cuarzofeldespático), predominando la composición pelítica en todos los sectores. Esporádicamente, se encuentran cuerpos de anfibolita en forma de lentes o diques concordantes con la dirección de la foliación principal del Ortoneis y pegmatitas que intruyen al Ortoneis de forma concordante y discordante con la foliación de este. La estructura predominante es la néisica, observándose ocasionalmente la estructura ojosa, maciza y augen. La foliación de la roca con estructura néisica dominante es en dirección NW. Los contactos con la roca encajante son de carácter intrusivo o fallado.

Las rocas estudiadas corresponden a neis cuarzofeldespático con biotita y hornblenda (muestra VR-7-2) y neis cuarzo-feldespático con biotita y muscovita (VR-22-1).

A continuación, se presenta una descripción de estas litologías.

\subsection{Neis cuarzo-feldespático con biotita $y$ hornblenda (muestra VR-7-2)}

Este ortoneis se localiza al este de la falla de Bábega y al SW del mismo corregimiento sobre la carretera hacia Chitagá (Latitud $7^{\circ} 10^{\prime} 47^{\prime}$, Longitud 7242'16”) (Fig. 2).

Este neis tiene una composición granítica, con foliación bien desarrollada y textura lepidogranoblástica. Las texturas pertítica y mirmequítica también se encuentran presentes en este tipo de composición.

Los minerales principales son cuarzo, plagioclasa, feldespato potásico, biotita y hornblenda. Ocasionalmente se observa granate, apatito y titanita como minerales accesorios (Fig. 3A y B).

Feldespato potásico (51\%) se presenta como cristales homeoblásticos a heteroblásticos y subidioblásticos, algunos de forma tabular y terminaciones irregulares. Presenta inclusiones de granate, apatito y circón. Se encuentra en contacto neto con plagioclasa, cuarzo, hornblenda y biotita. La macla en enrejado solo se aprecia hacia los bordes de los cristales con claridad. Suele observarse intercrecimiento pertítico con la plagioclasa. Algunos cristales se observan alterados a caolín hacia los bordes. Plagioclasa (10\%) ocurre como individuos heteroblásticos y subidioblásticos, algunos de forma tabular alargada y corta y con maclado polisintético característico. Se encuentra en contacto neto con biotita, cuarzo y feldespato potásico. Presenta inclusiones de apatito y granate. Suele observarse intercrecimiento mirmequítico con cuarzo. Se observa sericitización débil hacia los bordes. Biotita (3\%) en cristales de color marrón, homeoblásticos y subidioblásticos de forma tabular con inclusiones de circón y minerales opacos. Se encuentra en contacto neto con plagioclasa, feldespato potásico y cuarzo. La orientación preferencial de la biotita define la foliación principal de la roca. Algunos cristales se encuentran alterados a clorita. El Cuarzo (33\%) ocurre como individuos heteroblásticos e idioblásticos de forma tabular. Presenta inclusiones de hornblenda y biotita. Se encuentra en contacto neto con biotita, plagioclasa y feldespato potásico. Hornblenda (2\%) se presenta como cristales homeoblásticos y subidioblásticos de forma tabular. Presenta inclusiones de esfena. Se encuentra en contacto neto con feldespato potásico y biotita. Algunos cristales se observan parcialmente alterados a biotita y clorita. Granate $(0,4 \%)$ se presenta en la roca como mineral accesorio incluido en plagioclasa y feldespato potásico, con individuos 
de forma anhedral, relieve alto y forma esqueletal. Apatito $(0,4 \%)$ se presenta como cristales tabulares de relieve alto incluidos en cristales de plagioclasa y feldespato potásico. Esfena $(0,2 \%)$ ocurre como individuos heteroblásticos, idioblásticos, alargados y algunos de forma romboédrica, predominando los alargados. Se encuentran como inclusiones en los cristales de hornblenda.

La paragénesis principal es $\mathrm{Fsp}+\mathrm{Qz}+\mathrm{Pl} \pm \mathrm{Bt} \pm \mathrm{Hbl}$ (feldespato potásico-cuarzo-plagioclasa-biotitahornblenda).

\subsection{Neis cuarzo-feldespático con biotita y muscovita (VR-22-1)}

Este ortoneis aflora a ocho kilómetros en dirección NW del municipio de Silos, cerca del río Cáraba (Latitud 7¹2’44” Longitud 7246’39”) (Fig. 2).
Este neis de composición granodiorítica registra intensa deformación y recristalización. La deformación está ocasionada por la falla $\mathrm{La}$ Estancia. (Fig. 3C y D).

La roca presenta textura porfidoblástica en matriz lepidogranoblástica, donde los blastos de la roca son de plagioclasa, feldespato potásico y cuarzo formando microlitones. La matriz es de biotita, muscovita, cuarzo, feldespato potásico y plagioclasa y forman el clivaje de la roca. En algunos cristales de feldespato potásico se observa textura gráfica.

Feldespato potásico $(16 \%)$ se presenta en cristales heteroblásticos y subidioblásticos, algunos de forma tabular y con maclado en rejilla característico. Se observan dos tipos de feldespato potásico: El tipo 1 son porfidoblastos formando microlitones junto con plagioclasa y cuarzo, y el tipo 2 , son cristales más pequeños haciendo parte de la matriz y, junto con biotita, muscovita, cuarzo y plagioclasa

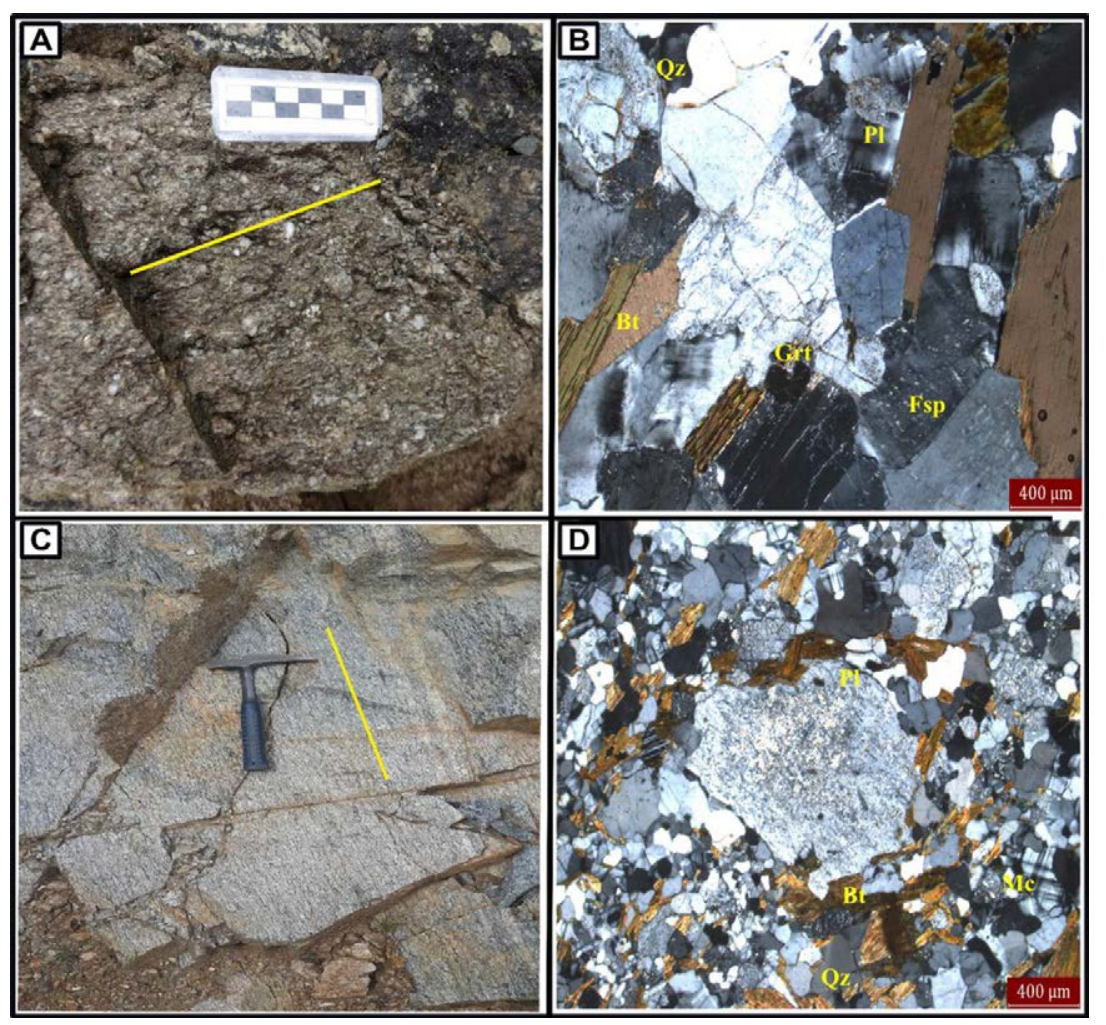

FIG 3. Características petrográficas del Ortoneis. A-B. Foliación del neis cuarzo-feldespático con biotita y hornblenda y textura lepidogranoblástica (muestra VR-7-2); C-D. Foliación bien desarrollada y textura lepidogranoblástica con evidencias de recristalización posdeformación en neis cuarzo-feldespático con biotita y muscovita (muestra VR-22-1). Qz: cuarzo; PI: plagioclasa; Bt: biotita; Grt: granate; Fsp: feldespato potásico; Mc: muscovita. 
forman los dominios de clivaje de la roca. Algunos cristales presentan inclusiones de biotita y cuarzo. Los porfidoblastos de feldespato potásico están en contacto neto con cuarzo y plagioclasa, mientras que el feldespato potásico 2 que forma parte de la matriz, se encuentra en contacto neto con plagioclasa, cuarzo y biotita. En algunos cristales se observa textura gráfica. Plagioclasa (32\%) ocurre en cristales heteroblásticos y subidioblásticos, algunos de forma tabular y con maclado polisintético. Está presente como porfidoblastos y haciendo parte de la matriz, predominando el primero y formando microlitones junto con el feldespato potásico y el cuarzo. Los blastos de plagioclasa se encuentran en contacto neto con feldespato potásico y cuarzo, mientras los cristales de la matriz se encuentran en contacto neto con biotita, muscovita, cuarzo y feldespato potásico 2. En algunos blastos se observa desplazamiento de las maclas y venas de sericita. La mayoría de porfidoblastos se encuentran alterados a sericita en el centro y borde. Cuarzo (40\%) ocurre como individuos heteroblásticos y subidioblásticos a homeoblásticos, algunos redondeados y otros de forma tabular. Se encuentra en la roca como porfidoblastos y formando la matriz. Los cristales de la matriz se encuentran en contacto neto con feldespato potásico 2 y biotita y forman el clivaje de la roca. Los porfidoblastos se encuentran en contacto con el feldespato potásico y la biotita. Se presenta como agregados donde se observa la individualización de los blastos y la formación de caras bien definidas. Los cristales presentan extinción ondulosa. Biotita (7\%) se observa en cristales de color marrón, heteroblásticos y subidioblásticos de forma tabular. Se presenta en la roca formando la foliación principal y haciendo parte de la matriz. Se encuentra en contacto neto con el cuarzo y feldespato potásico. Algunos cristales están alterando a clorita y presentan inclusiones de muscovita. Muscovita (3\%) presenta cristales incoloros heteroblásticos y subidioblásticos de forma tabular y constituyen parte de la matriz de la roca. Se encuentra en contacto neto con la biotita, feldespato potásico y cuarzo.

La paragénesis del pico metamórfico es $\mathrm{P} 1+\mathrm{Fsp}+\mathrm{Qz} \pm \mathrm{Bt}$ (plagioclasa-feldespato potásicocuarzo-biotita).

\section{Geoquímica}

Se analizó el contenido de elementos mayores, menores y elementos de las tierras raras en los neises estudiados y se compararon con resultados recientemente obtenidos por Van der Lelij et al. (2015) en ortoneises de los sectores SW de Vetas y SW de Pamplona (Apéndice 1).

La composición química del neis cuarzo-feldespático con biotita y hornblenda (muestra VR-7-2) y neis cuarzo-feldespático con biotita y muscovita (VR-22-1) se muestra en la tabla 1. Las rocas estudiadas pertenecen a la serie calcoalcalina rica en potasio según Peccerillo y Taylor, 1976 (Fig. 4A), excepto una, que es calcoalcalina normal. El índice de saturación en alumina de Shand (1943), basado en la relación $\mathrm{Al}_{2} \mathrm{O}_{3} /\left(\mathrm{CaO}+\mathrm{Na}_{2} \mathrm{O}+\mathrm{K}_{2} \mathrm{O}\right)$ con valores entre 1,47 y 1,49 , indican el carácter peraluminoso de estos ortoneises (Fig. 4B).

El diagrama de los elementos de las tierras raras (REE por sus siglas en inglés) normalizado a la corteza superior (Taylor and McLennan, 1981), de forma general, muestra un patrón de empobrecimiento en tierras raras livianas respecto a las tierras raras pesadas, este patrón, es más notorio en la muestra VR-22-1, la cual a su vez se encuentra más empobrecida en su contenido total de REE respecto a la muestra VR-7-2, ambas con anomalías negativas de Europio. Los valores de fraccionamiento son: $\mathrm{La} / \mathrm{Yb}$ de 0,35 y $0,57, \mathrm{La} / \mathrm{Sm}$ de 0,75 y $0,81, \mathrm{Gd} / \mathrm{Yb}$ de 0,55 y 0,93 para las muestras VR-22-1 y VR-7-2 respectivamente. El diagrama spider normalizado también a la corteza superior (Taylor y McLennan, 1985) muestra enriquecimientos en $\mathrm{Th}, \mathrm{K}, \mathrm{Nd}, \mathrm{Sm}, \mathrm{Y}, \mathrm{La}, \mathrm{Yb}$ y empobrecimiento en $\mathrm{Ba}, \mathrm{Nb}, \mathrm{Sr}, \mathrm{Tb}$ (Fig. 5A y B).

En los diagramas de discriminación tectónica de Harris et al. (1986) y Pearce et al. (1984), las muestras del Ortoneis se localizan en el campo de los granitos de arco volcánico (VAG, iniciales en inglés de volcanic arc granite), pero muy cercanos al campo de los granitos sincolisionales y granitos de intraplaca (Fig. 6A y B). No obstante lo anterior, y considerando el emplazamiento sintectónico (foliaciones concordantes de los ortoneises y los Esquistos del Silgará), es más probable que el protolito del Ortoneis corresponda a granitos sincolisionales.

Las características geoquímicas de las rocas del Ortoneis son concordantes con las obtenidas por Van der Lelij et al. (2015). Estos autores mencionan entre otros: 1. Rangos en el contenido de $\mathrm{SiO}_{2}$ entre $54 \%$ y $75 \%$; 2 . Serie calcoalcalina alta en $\mathrm{K}$; 3. Variaciones en el Índice de Shand y relaciones variables entre $\mathrm{Na}_{2} \mathrm{O}$ y $\mathrm{K}_{2} \mathrm{O}$ sugieren la presencia 


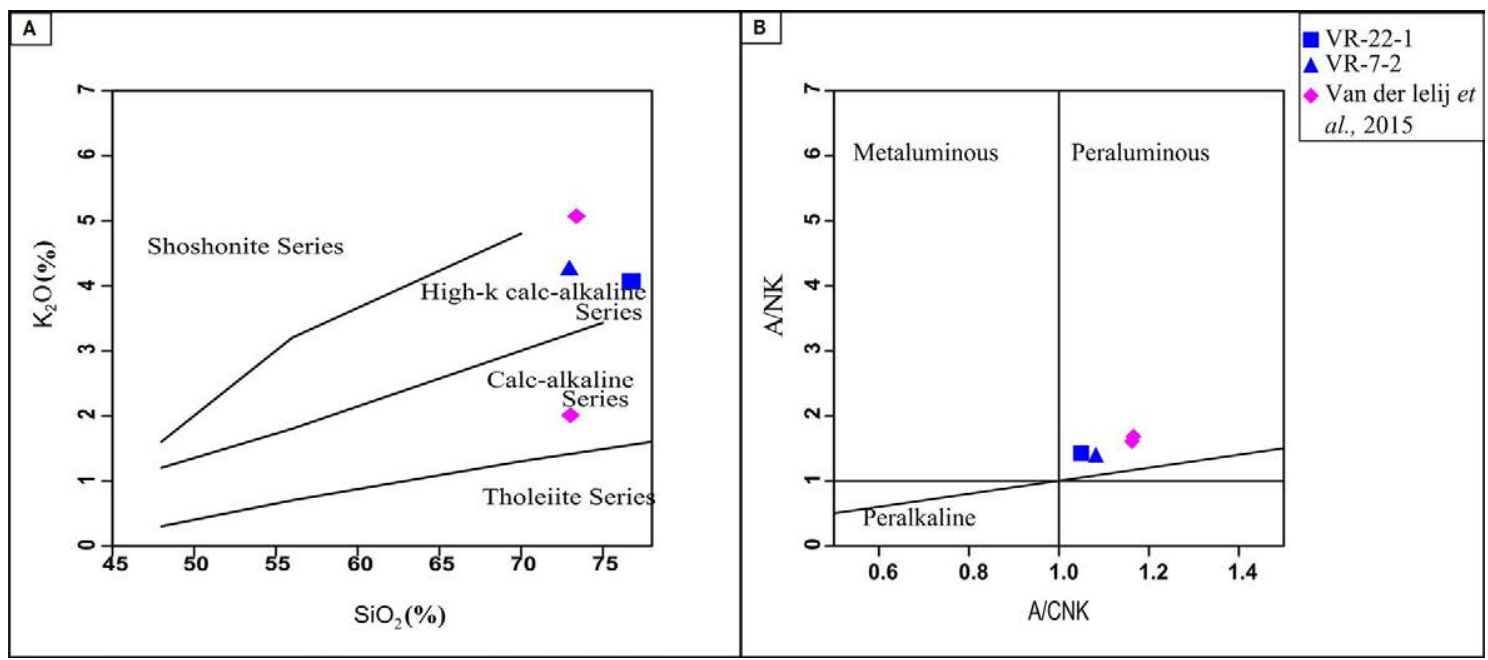

FIG 4. Disposición del Ortoneis en los diagramas de clasificación química para rocas plutónicas. A. Diagrama $\mathrm{SiO}_{2}$ versus $\mathrm{K}_{2} \mathrm{O}$ de Peccerillo y Taylor (1976). B. Diagrama de saturación en alumina A/CNK de (Shand, 1943).

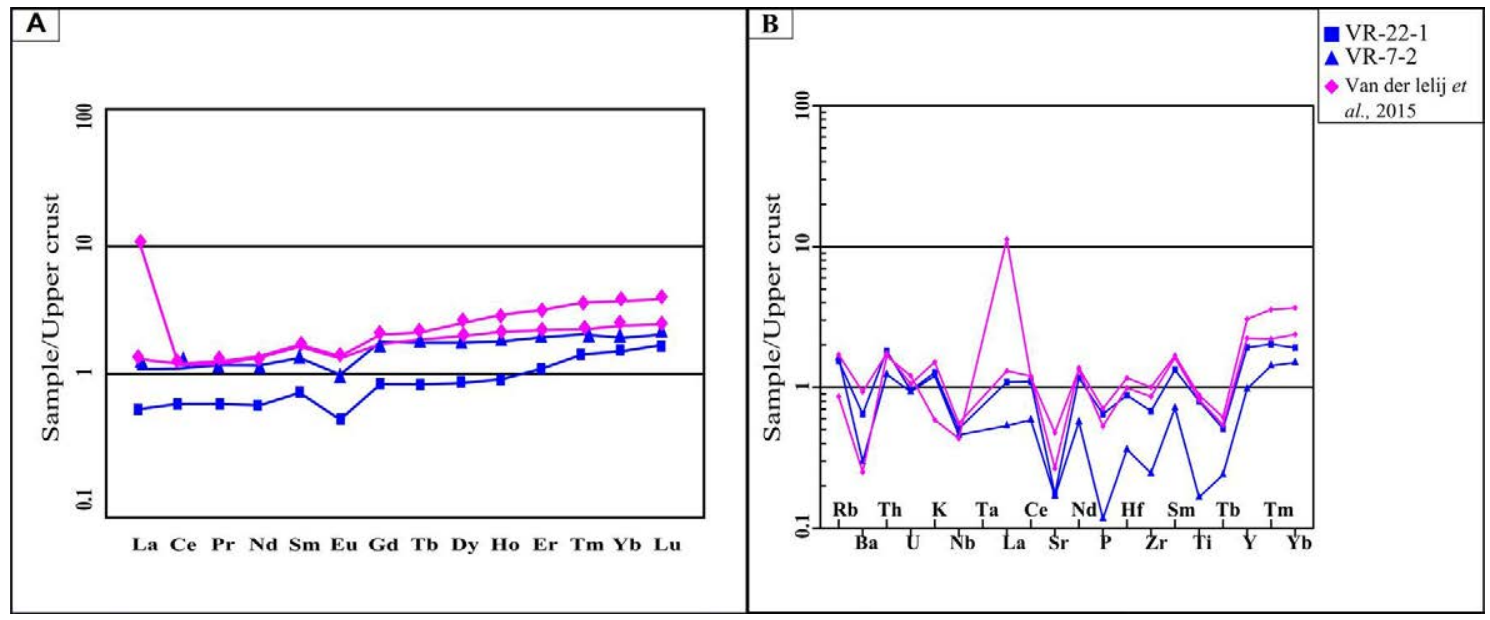

FIG 5. Diagramas de elementos multivariables. A. Diagrama de tierras raras de Taylor y McLennan (1981) normalizado a la corteza superior; B. Diagrama spider de Taylor McLennan (1985) normalizado a la corteza superior.

tanto de granitos tipo I y S (Chappell y White, 1974) los cuales fueron coetáneos; 4. Las rocas ígneas del Paleozoico Temprano pueden ser un resultado de la mezcla de proporciones variables de masas fundidas derivadas de diferentes fuentes (Maas et al., 1997; Patiño-Douce, 1999); 5. Contenido de elementos traza muy similar al promedio de la corteza continental superior (Taylor y McLennan,1985), con la excepción de las concentraciones de $\mathrm{Nb}$ y Ta; 6. Los bajos contenidos de $\mathrm{Nb}$ e Y de la mayoría de rocas son característicos de las que se formaron en márgenes convergentes (Pearce, 1996) y 7. La abundancia de REE son generalmente similares a la de la corteza continental superior, con anomalías negativas en europio.

\section{Metamorfismo}

Las condiciones P-T de las rocas estudiadas fueron determinadas mediante el programa THERIAKDOMINO, versión 03/01/2012 (De Capitani y Petrakakis, 2010) con la base de datos termodinámica 


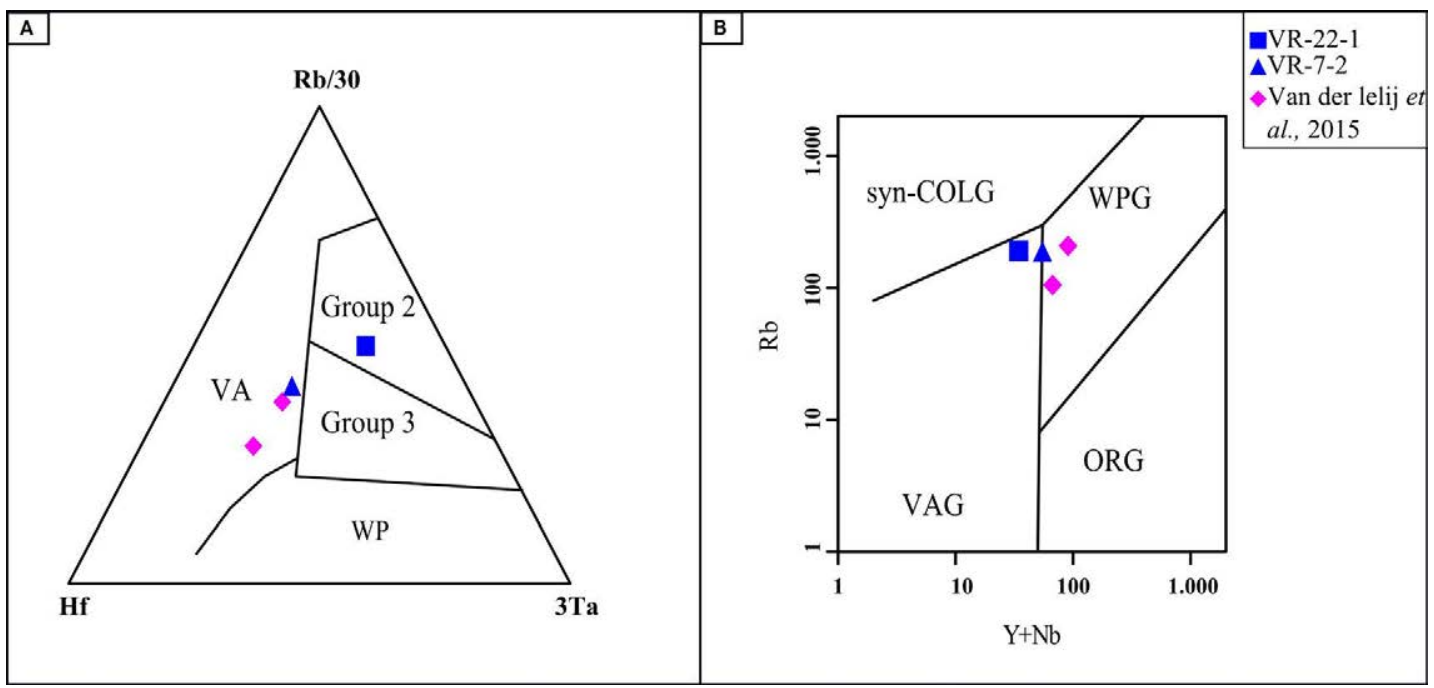

FIG 6. Diagramas de discriminación tectónica para las rocas del Ortoneis. A. Harris et al. (1986) y B. Pearce et al. (1984). Syn-COLG: granitos sin-colisionales; WPG-WP: granitos de intraplaca; VAG-VA: granitos de arco volcánico; ORG: granitos de dorsal oceánica; Grupo 2: intrusiones sin-colisionales peraluminosas; Grupo 3: intrusiones calco-alcalinas poscolisionales.

JUN92.bs de Berman (1988). Se construyeron los diagramas para el sistema NKFCMASH $\left(\mathrm{Na}_{2} \mathrm{O}\right.$, $\mathrm{K}_{2} \mathrm{O}, \mathrm{FeOtot}, \mathrm{CaO}, \mathrm{MgO}, \mathrm{Al}_{2} \mathrm{O}_{3}, \mathrm{SiO}_{2}$ y $\mathrm{H}_{2} \mathrm{O}$ ).

La paragénesis del pico metamórfico del neis cuarzo-feldespático con biotita (muestra VR-22-1) corresponde a $\mathrm{Pl}+\mathrm{Fsp}+\mathrm{Qz}+\mathrm{Bt}$. En la seudosección obtenida, esta asociación es estable en las condiciones entre 6,5 y $10 \mathrm{~Kb}$ de presión y 540 y $800{ }^{\circ} \mathrm{C}$ de temperatura. Este ortoneis sufrió intensa deformación, y al parecer en la etapa pospico se formó muscovita y fases recristalizadas de plagioclasa, feldespato potásico, cuarzo y biotita. La asociación $\mathrm{Pl}+\mathrm{Fsp}+\mathrm{Qz}+\mathrm{Bt}+\mathrm{Ms}$ representa esta etapa de recristalización ocurrida a una temperatura entre $550-600{ }^{\circ} \mathrm{C}$ y presión entre 6 y $10 \mathrm{~Kb}$ (Fig. 7). La etapa retrograda es marcada por la formación de clorita después de biotita y sericita después de plagioclasa.

La seudosección del neis cuarzo-feldespático con hornblenda, biotita y granate (muestra VR-7-2), indica condiciones entre 4,3-9 $\mathrm{Kb}$ de presión y $660-800{ }^{\circ} \mathrm{C}$ de temperatura para la paragénesis del pico metamórfico $\mathrm{Pl}+\mathrm{Fsp}+\mathrm{Bt} \pm \mathrm{Hbl} \pm \mathrm{Grt}+\mathrm{Qz}$. El reemplazo parcial de hornblenda por biotita y clorita indica la etapa retrograda del metamorfismo. Estas condiciones corresponderían a 5,5-7,5 $\mathrm{Kb}$ de presión y $630-690^{\circ} \mathrm{C}$. Parte de la etapa retrógrada se presenta en la figura 8 .

\section{Geocronología}

Dos rocas del Ortoneis muestra VR-7-2 (Neis cuarzo-feldespático con biotita y hornblenda) y muestra VR-22-1 (Neis cuarzo-feldespático con biotita y muscovita) fueron analizadas mediante U/Pb LA-ICP-MS (Apéndice 2).

En la muestra VR-7-2, los circones están zonados y son alargados o isométricos. La zonación puede ser simétrica a asimétrica, un tanto truncada, aunque algunos no presentan zonación. La edad de $479 \pm 10 \mathrm{Ma}$ representa la edad de emplazamiento y metamorfismo. Las edades en torno a 1000 Ma y más antiguas hasta $1600 \mathrm{Ma}$ son edades heredadas obtenidas de los núcleos de algunos circones (Figs. 9 y 10A).

La muestra VR-22-1 presenta circones con zonación simple simétrica a compleja asimétrica. Por lo general son cristales alargados, rara vez isométricos azonados. La edad de $471 \pm 11$ Ma es muy similar a la edad de la muestra VR-7-2. A diferencia de esta última muestra, muy pocos circones presentan edades heredadas, solo 4 en torno a 507-514 Ma y solo una de 2096 Ma (ver Figs. 9 y 10B).

\section{Discusión}

La unidad Ortoneis en el Macizo de Santander comprende neises pelíticos, cuarzo-feldespáticos 


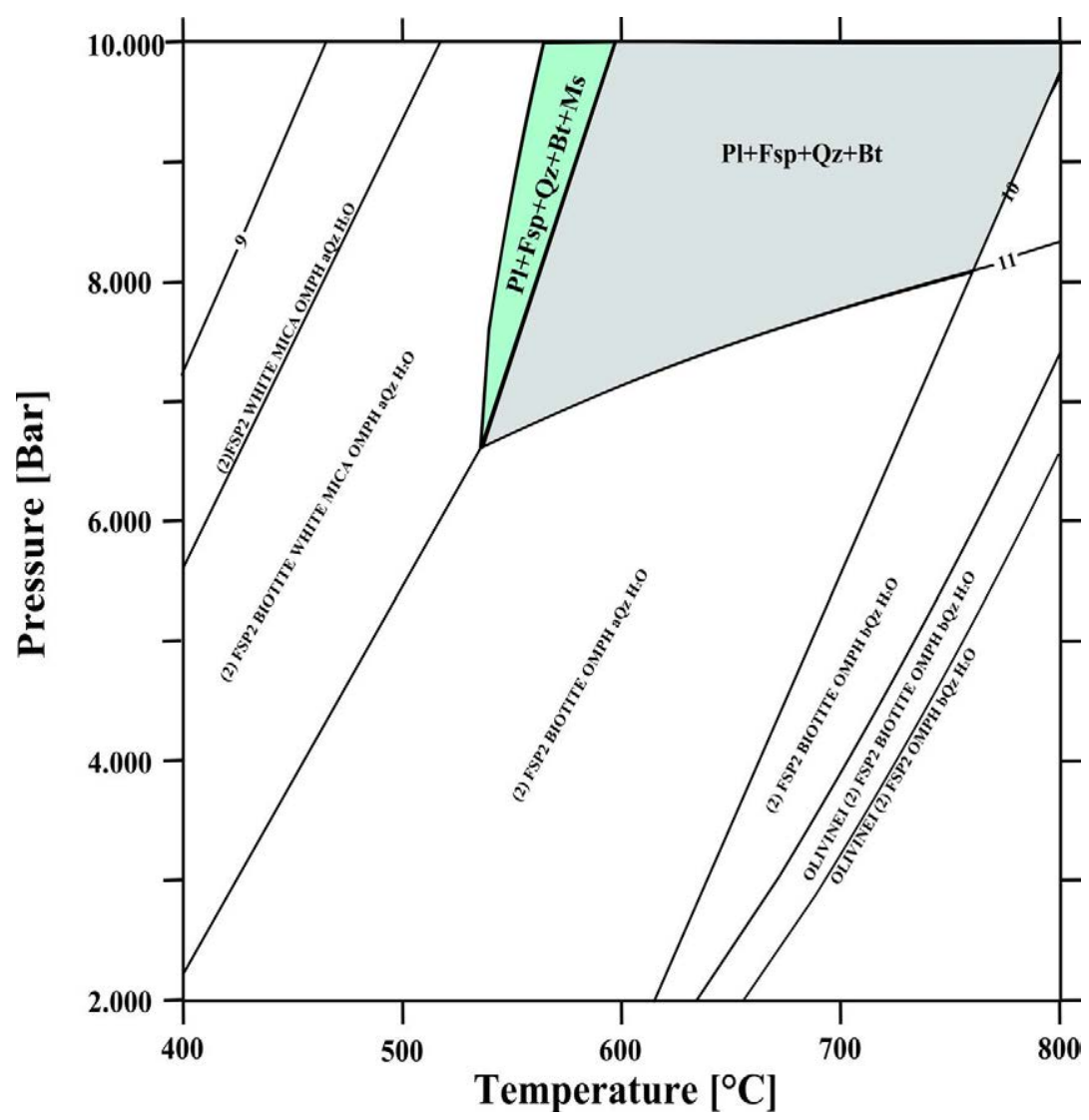

FIG 7. Seudosección para la muestra VR-22-1. Máximas condiciones P-T alcanzadas (campo gris), condiciones de recristalización posdeformación (campo verde claro).

y hornbléndicos con lentes de anfibolita, cuyos protolitos se emplazaron de forma sintectónica en rocas de la unidad Esquistos de Silgará. Este emplazamiento tectónico se evidencia por la presencia de foliaciones con similar orientación y por el igual grado de metamorfismo alcanzado en ambas unidades (Restrepo-Pace et al., 1997; García et al., 2005; Castellanos et al., 2008; Rey y García, 2015; Van der Lelij et al., 2015).

Las variaciones composicionales, texturales y microestructurales en estos neises se atribuyen principalmente a variaciones en el protolito $\mathrm{y}$ diferentes niveles corticales de emplazamiento, así como la anatexis sufrida por algunos cuerpos de ortoneises, reportada por Van der Lelij et al. (2015). La composición de los ortoneises como se indicó en apartados anteriores es diversa. Esto podría explicarse a partir entre otros, de la presencia de granitos tipo I y $\mathrm{S}$, evidenciado por las relaciones variables entre $\mathrm{Na}_{2} \mathrm{O}$ y $\mathrm{K}_{2} \mathrm{O}$, no tan marcados en este estudio, pero sí, bastante contrastantes en las rocas estudiadas por Van der Lelij et al. (2015). Las relaciones texturales entre cuarzo y biotita en un ortoneis estudiado cerca de Berlín son interpretados por Van der Lelij et al. (2015) como producto de anatexis que afectó algunos neises poco después del evento metamórfico. Estos autores también respaldan esta afirmación apoyados en la dispersión de edades $(483,3 \pm 5,7$ Ma y $462,7 \pm 3,4$ Ma con MSWD $=11,5$ ), obtenidas en esta misma muestra. Estas edades, según estos autores, indicarían cristalización y posterior anatexis. El grado de metamorfismo y la actividad tectónica que afectó a las rocas con protolitos granitoides influyó en un mejor desarrollo de la foliación con formación de bandas mineralógicas bien diferenciadas. $\mathrm{Al}$ respecto, también Van der Lelij et al. (2015) señalan que un ortoneis de composición tonalitica $(451,5 \pm 1,3 \mathrm{Ma})$ intruyó Esquistos del Silgará, de menor grado metamórfico, siendo la foliación de este ortoneis 


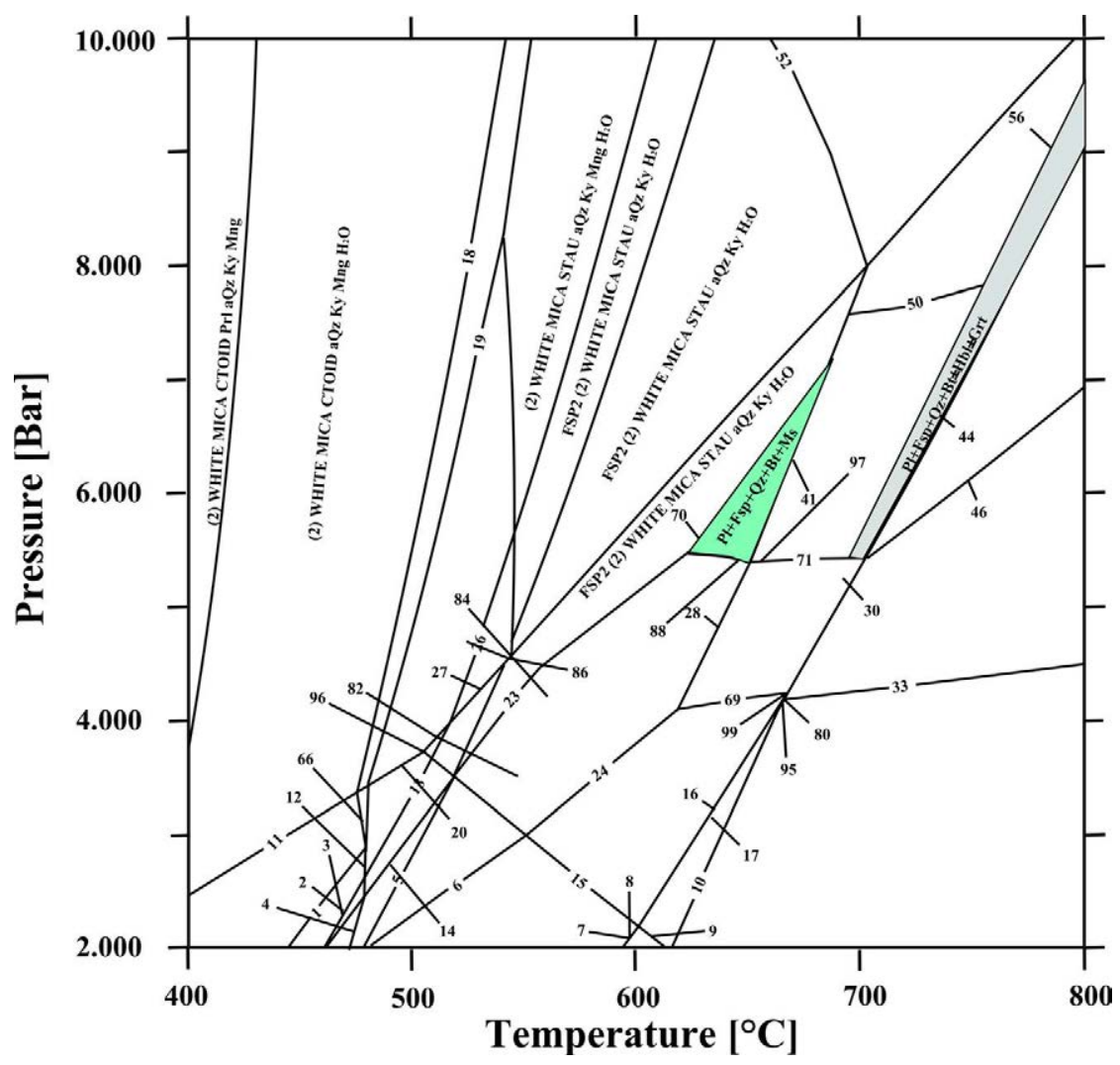

FIG 8. Seudosección para la muestra VR-7-2. Máximas condiciones P-T alcanzadas (campo gris), condiciones retrógradas (campo verde claro).

\section{VR-22-1}

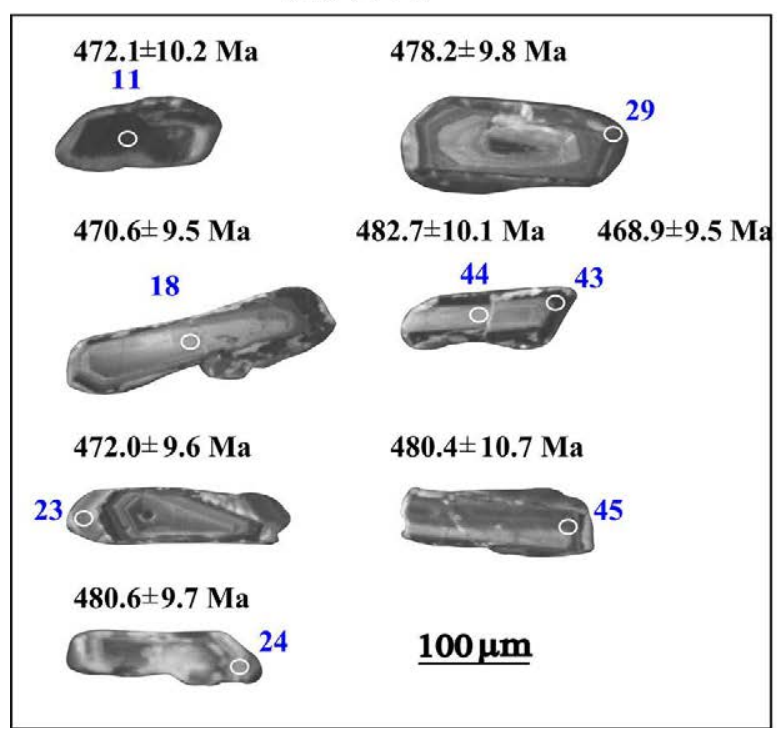

VR-7-2

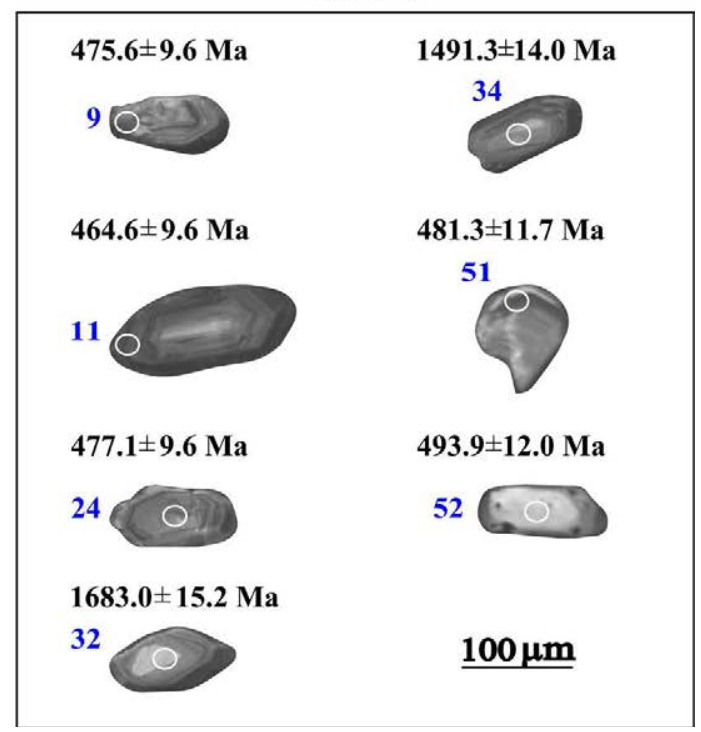

FIG 9. Imágenes de catodoluminiscencia de circones representativos en las muestras analizadas. 

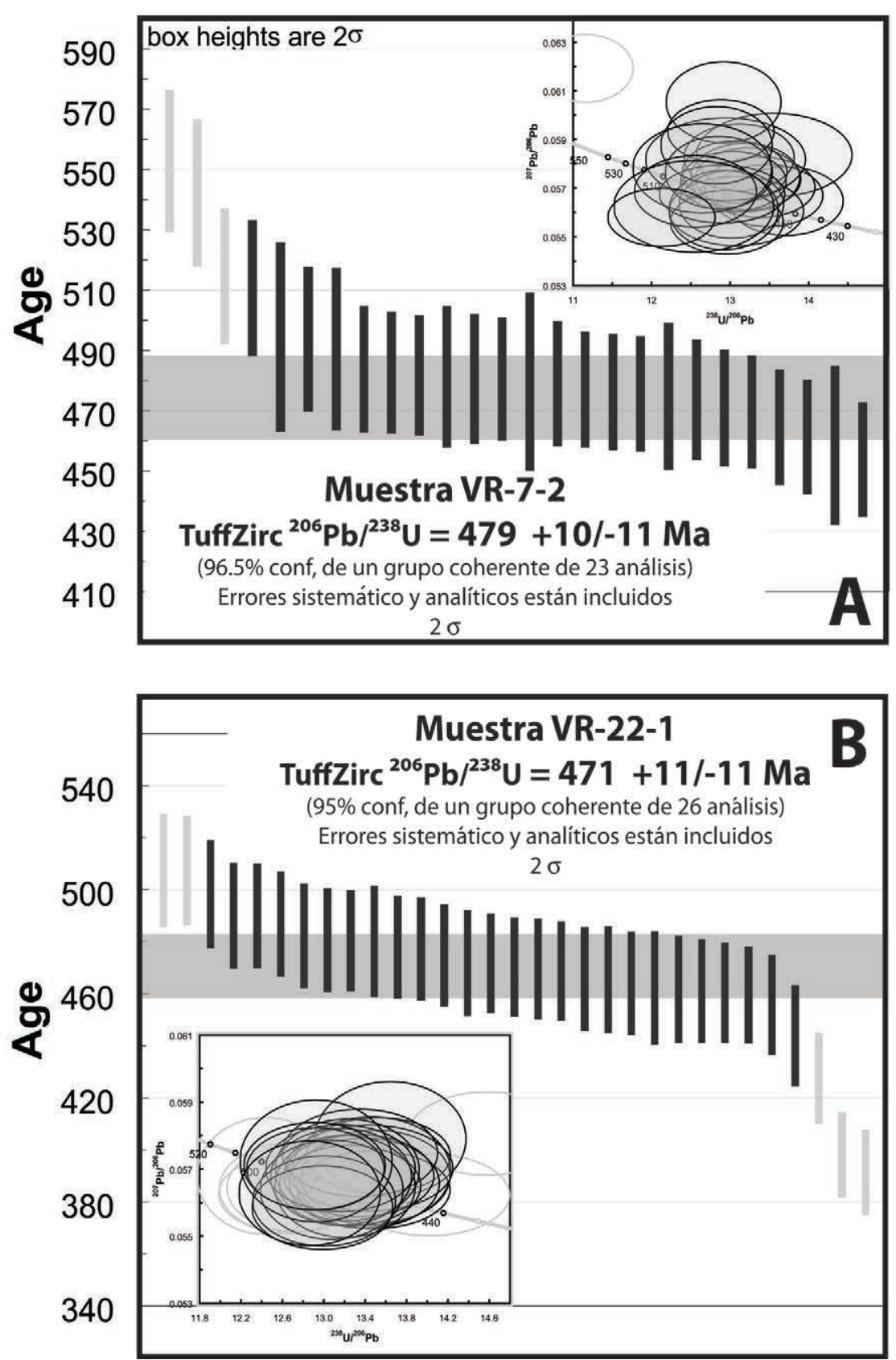

FIG 10. Diagramas concordia U-Pb en circones del Ortoneis. A. Muestra VR-7-2. B. Muestra VR-22-1.

más débil que en otros sectores del Macizo de Santander. El grado de metamorfismo alcanzado y el desarrollo de la foliación en ortoneises y roca encajante podría estar relacionado también con la profundidad, lo que explicaría diferentes niveles corticales de emplazamiento de los ortoneises.
Las edades obtenidas en este estudio de $479 \pm 10 \mathrm{Ma}$ y $471 \pm 11$ Ma son consistentes con las edades obtenidas por Ward et al. (1973), Restrepo-Pace (1995), Mantilla et al. (2012) y Van der Lelij et al. (2015). Estos conjuntos de edades indican que las rocas del Ortoneis representan la Orogenia Quetame-Caparonensis 
conocida como Famatiniana en los Andes del Sur (Argentina, Chile, Bolivia). Edades similares han sido obtenidas por Van der Lelij et al. (2015) en los Andes de Mérida (Venezuela). Estos autores concluyen que ambos macizos son autóctonos a Gondwana y comparten una historia geológica común con el margen de Gondwana de Perú, Chile y Argentina.

El emplazamiento del Ortoneis se ha considerado como sintectónico al pico de metamorfismo de la unidad Esquistos de Silgará de acuerdo con la relación de campo (contacto intrusivo con foliaciones concordantes de estas dos unidades). Sin embargo, algunos ortoneises exhiben foliación débil, lo cual indicaría un emplazamiento pospico en la unidad Esquistos de Silgará y corresponderían a las edades del Ordovícico Medio y Superior reportadas por los autores mencionados anteriormente. En este sentido, edades $\mathrm{U}-\mathrm{Pb}$ en circones detríticos en torno a $452 \pm 7,7 \mathrm{Ma}$ reportadas como máxima edad de depositación de metasedimentitas conocidas como Filitas de San Pedro representan un aporte de rocas del Ortoneis del Ordovícico Tardío (Mantilla et al., 2016a y b).

Los ortoneises que se emplazaron en la etapa postpico en niveles corticales superiores podrían haber generado un metamorfismo de contacto con formación de sillimanita en rocas de la unidad Esquistos de Silgará. Evidencia de esto, se presenta en el sector central del MS, en la zona de Ranchadero, en donde afloran cuarcitas y esquistos pelíticos con presencia de abundante silimanita fibrolítica. En este lugar el neis cuarzo-feldespático con biotita presenta un débil desarrollo de la foliación.

Los resultados obtenidos en este trabajo indican que rocas del Ortoneis en sectores antes no estudiados corroboran un evento de emplazamiento durante el Ordovícico Temprano. Este evento ha sido ampliamente registrado y documentado en los Andes Centrales y del Sur por Alemán y Ramos (2000) y Rapela et al. (2001), entre otros. Adicional a esto, los estudios adelantados por Pankhurst et al. (2000) y Dalquist et al. (2008) indican que el magmatismo del arco famatiniano en Argentina es más antiguo que $465 \mathrm{Ma}$. Los datos obtenidos en este trabajo son consistente con la idea de que la Orogenia Famatiniana también afectó al protomargen andino en los Andes del Norte.

\section{Conclusiones}

Las rocas del Ortoneis en el sector SE del Macizo de Santander son neises cuarzo-feldespáticos con biotita y neises cuarzo-feldespáticos con hornblenda $\mathrm{y}$ granate.

Las características mineralógicas y geoquímicas indican que son rocas de composición granodiorítica y granítica emplazadas en ambientes de arco continental activo o correspondientes a granitos sincolisionales.

El emplazamiento del Ortoneis fue sintectónico y ocurrió durante el pico metamórfico de los Esquistos de Silgará, en facies de anfibolita.

Las edades de $479 \pm 10$ Ma y $471 \pm 11$ Ma obtenidas son concordantes con edades de Ortoneis de la parte central del MS y evidencian un evento tectonotermal asociado a la Orogenia Famatiniana, la que representa a su vez, el protomargen andino que se extendió desde MS hasta los Andes del Sur (NE de Argentina, Sur de Bolivia, NE de Chile, SW de Perú).

\section{Agradecimientos}

El presente trabajo fue financiado por Colciencias y la Universidad Industrial de Santander-UIS mediante el Proyecto 110156933549 (código UIS 9435) Estructura y evolución geológica del basamento cristalino del Macizo de Santander, Cordillera Oriental (Colombia). A estas entidades los autores expresan su agradecimiento.

Los autores están más que agradecidos con los doctores U. Cordani y R. Pankhurst por la revisión crítica del trabajo y cuyos comentarios y observaciones contribuyeron a mejorar el mismo.

\section{Referencias}

Alemán, A.; Ramos, V.A. 2000. The Northern Andes. In Tectonic Evolution of South America, Río de Janeiro, Brazil (Cordani, U.G.; Milani, E.J.; Thomaz, A.; Campos, D.A.; editors). In International Geological Congress, No. 31: 453-480. Río de Janeiro.

Berman, R. 1988. Internally-consistent thermodynamic data for minerals in the system $\mathrm{Na}_{2} \mathrm{O}-\mathrm{K}_{2} \mathrm{O}-\mathrm{CaO}$ $\mathrm{MgO}-\mathrm{FeOFe} \mathrm{O}_{3}-\mathrm{Al}_{2} \mathrm{O}_{3}-\mathrm{SiO}_{2}-\mathrm{TiO}_{2}-\mathrm{H}_{2} \mathrm{O}-\mathrm{CO}_{2}$. Journal of Petrology 29 (2): 445-552.

Boinet, T.; Bourgois, J.; Bellon, H.; Toussaint, J. 1985. Age et repartition du Age et répartition du magmatisme Prémésozoïque des Andes de Colombie=Age and distribution of the Premesozoic magmatism of the Andes of Columbia. Comptes-rendus des séances de L'Académie des Sciences. Serie 2, MécaniquePhysique, chimie, sciences des L'univers, sciences de la terre 300 (2): 445-450.

Cardona, A.; Valencia, V.A.; Lotero, A.; Villafáñez, Y.; Bayona, G. 2016. Provenance of middle to late Palaeo- 
zoic sediments in the northeastern Colombian Andes: implications for Pangea reconstruction. International Geology Review 58 (15): 1914-1939.

Castellanos, A.O.M.; Ríos, R.C.A.; Takasu, A. 2008. A new approach on the tectonometamorphic mechanisms associated with p-t paths of the barrovian-type silgará formation at the central Santander Massif, Colombian Andes. Earth Sciences Research Journal 12 (2): 125-155.

Cediel, F.; Shaw, R.; Caceres, C. 2003. Tectonic assembly of the Northern Andean Block (Bartolini, C.; Buffler, R.T.; Blickwede, J.; editors). The Circum-Gulf of Mexico and the Caribbean: Hydrocarbon habitats, basin formation, and plate tectonics: American Association of Petroleum Geologists (AAPG), Memoir 79: 815-848.

Chang, Z.; Vervoort, J.D.; McClelland, W.C.; Knaack, C. 2006. U-Pb dating of zircon by LA-ICP-MS. Geochemistry Geophysics Geosystems 7: 1-14.

Chappell, B.; White, A. 1974. Two contrasting granite types. Pacific Geology 8: 173-174.

Cordani, U.; Cardona, A.; Jiménez, D.; Liu, D.; Nutman, A. 2005. Geochronology of Proterozoic basement inliers in the Colombian Andes: tectonic history of remnants of a fragmented grenville belt. In Terrane processes at margins of Gondwana (Vaughan, A.P.M.; Leat, P.T.; Pankhurst, R.J.; editors). Geological Society of London, Special Publications 246: 329-346.

Dahlquist, J.A.; Pankhurst, R.J.; Rapela, C.W.; Galindo, C.; Alasino, P.; Fanning, C.M.; Saavedra, J.; Baldo, E. 2008. New SHRIMP U-Pb data from the Famatina Complex: constraining Early-Mid Ordovician Famatinian magmatism in the Sierras Pampeanas, Argentina. Geologica Acta 6: 319-333.

De Capitani, C.; Petrakakis, K. 2010. The computation of equilibrium assemblage diagrams with Theriak/Domino software. American Mineralogist 95: 1006-1016.

Forero, A. 1990. The basamento of the Eastern Cordillera, Colombia. An allochthonous terrane in northwestern South America. Journal of South American Earth Sciences 3 (2): 141-151.

Gansser, A. 1973. Facts and theories on the Andes. Journal of the Geological Society 129 (2): 93-131. London.

García, R.C.A.; Ríos, R.C.A.; Castellanos, A.O.M. 2005. Medium-pressure metamorphism in the Central Santander Massif, Eastern Cordillera, Colombian Andes. Boletín de Geología 27 (2): 43-68.

Goldsmith, R.; Marvin, R.F.; Mehnert, H.H. 1971. Radiometric ages in the Santander Massif, Eastern
Cordillera, Colombian Andes. Geological Survey Research 750-D: 44-49.

Harris, N.B.W.; Pearce, J.A.; Tindle, A.G. 1986. Geochemical characteristics of collision-zone magmatism. In Collision tectonics (Coward, M.P.; Reis, A.C.; editors). Geological Society of London Special Publications 19: 67-81. doi: 10.1144/GSL.SP.1986.019.01.04.

Janoušek, V.; Farrow, C.M.; Erban, V. 2006. Interpretation of whole-rock geochemical data in igneous geochemistry: introducing Geochemical Data Toolkit (GCDkit). Journal of Petrology 47 (6): 1255-1259.

Ludwig, K.; Mundil, R. 2002. Extracting reliable U-Pb ages and errors from complex populations of zircons from Phanerozoic tuffs. Geochimica et Cosmochimica Acta 66: p. 463.

Ludwig, K.R. 2003. Isoplot 3.0-A geochronological toolkit for Microsoft Excel: Berkeley, California. Berkeley Geochronology Center, Special publication 4: 71 p.

Maas, R.; Nicholls,I.; Legg, C. 1997. Igneous and metamorphic enclaves in the S-type Deddick Granodiorite, Lachlan Fold Belt, SE Australia: Petrographic, geochemical and $\mathrm{Nd}-\mathrm{Sr}$ isotope evidence for crustal melting and magma mixing. Journal of Petrology 38: 815-841.

Mantilla, F.L.C.; Bissig, T.; Cottle, J.M.; Hart, C.J.R. 2012. Remains of early Ordovician mantle-derived magmatism in the Santander Massif (Colombian Eastern Cordillera). Journal of South American Earth Sciences 38: 1-12.

Mantilla, F.L.C.; García, R.C.A.; Valencia, V.A. 2016a. Propuesta de escisión de la denominada "Formación Silgará" (Macizo de Santander, Colombia), a partir de edades U-Pb en circones detríticos. Boletín de Geología 38 (1): 33-50.

Mantilla, F.L.C.; García, R.C.A.; Valencia, V.A. 2016 b. Nuevas evidencias que soportan la escisión de la Formación Silgará y propuesta de un nuevo marco estratigráfico para el basamento metamórfico del Macizo de Santander (Cordillera Oriental de Colombia). Revista de la Academia Colombiana de Ciencias Exactas, Físicas y Naturales 40 (155): 320-336.

Paces, J.; Miller, J. 1993. Precise U-Pb ages of Duluth complex and related mafic intrusions, northeastern Minnesota; geochronological insights to physical, petrogenetic, paleomagnetic, and tectonomagmatic processes associated with the $1.1 \mathrm{Ga}$ midcontinent rift system. Journal of Geophysical Research 98 (B8): doi: 10.1029/93JB01159.

Pankhurst, R.J.; Rapela, C.W.; Fanning, C.M. 2000. Age and origin of coeval TTG, I- and S-type granites in 
the Famatinian belt of NW Argentina. Transactions of the Royal Society of Edinburgh. Earth Sciences 91: 151-168.

Patiño-Douce, A. 1999. What do experiments tell us about the relative contributions to the origin of granitic magmas? In Understanding granites. Integrating new and classical techniques (Castro, A.; Fernández, C.; Vigneresse, J.; editors). Geological Society of London Special Publications 158: 55-75.

Pearce, J.A. 1996. Sources and setting of granitic rocks. Episodes 19: 120-125.

Pearce, J.A.; Harris, N.B.W.; Tindle, A.G. 1984. Trace element discrimination diagrams for the Tectonic interpretation of granitic rocks. Journal of Petrology 25: 956-983.

Peccerillo, R.; Taylor, S.R. 1976. Geochemistry of Eocene calc-Alkaline volcanic rocks from the Kastamonu área, Northern Turkey. Contributions to Mineralogy and Petrology (58): 63-81.

Rapela, C.; Casquet, C.; Baldo, E.; Dalhquist, J.; Pankhurst, R.; Galindo, C.; Saavedra, J. 2001. Las orogenesis del Paleozoico Inferior en el margen proto-andino de America del Sur, Sierras Pampeñas, Argentina. Journal of Iberian Geology 27: 23-41.

Restrepo-Pace, P. 1995. Late Precambrian to Early Mesozoic tectonic evolution of the Colombian Andes based on new geochronological, geochemical and isotopic data. Ph.D. Thesis (Unpublished), University of Arizona: $195 \mathrm{p}$.

Restrepo-Pace, P.; Cediel, F. 2010. Northern South America basement tectonics and implications for paleocontinental reconstructions of the Americas. Journal of South American Earth Sciences (29): 764-771.

Restrepo-Pace, P.; Ruiz, J.; Gehrels, G.; Cosca, M. 1997. Geochronology and Nd isotopic data of Grenvilleage rocks in Columbian Andes: new constraints for Late Proterozoice Early Paleozoic paleocontinental reconstructions of Americans. Earth and Planetary Science Letters 155: 427-441.

Rey, V.; García, C. 2015. Petrología y geoquímica del ortoneis en el Macizo de Santander. In Congreso Colombiano de Geología, No. 15, Memorias: 646-652. Bucaramanga.

Ríos, R.C.A.; García, R.C.A.; Takasu, A. 2003. Tectonometamorphic evolution of the Silgara Formation Metamorphic rocks in the southwestern Santander Massif, Colombian Andes. Journal of South American Earth Sciences 16: 1-22.

Rollinson, Hugh. 1993. Using Geochemical Data: Evaluation, Presentation, Interpretation. Pearson Education Limited: 384 p. London.
Royero, G.J.M.; Clavijo, J. 2001. Mapa geológico generalizado del Departamento de Santander, escala 1:400.000. Memoria explicativa del Instituto Colombiano de Geología y Minería (INGEOMINAS): $92 \mathrm{p}$.

Shand, S.J. 1943. Eruptive rocks. Their genesis composition, classification and their relations to ore-deposits. John Wiley and Sons: 444 p. New York.

Sláma, J.; Kosler, J.; Condon, D.; Crowley, J.; Gerdes, A.; Hanchar, J.; Horstwood, M.; Morris, G.; Nasdala, L.; Norberg, N.; Schaltegger, U.; Schoene, B.; Tubrett, M.; Whitehouse, M. 2008. Plesovice zircon-a new natural reference material for $\mathrm{U}-\mathrm{Pb}$ and $\mathrm{Hf}$ isotopic microanalysis. Chemical Geology 249 (1-2): 1-35.

Taylor, S.R.; McLennan, S.M. 1981. The composition and evolution of the continental crust: rare earth element evidence from sedimentary rocks. Philosophical Transactions of the Royal Society of London A (301): 381-399. doi: 10.1098/rsta.1981.0119.

Taylor, S.R.; McLennan, S.M. 1985. The continental crust: its composition and evolution. Blackwell Scientific Publication, Carlton: $312 \mathrm{p}$.

Toussaint, J.F.; Restrepo, J.J. 1988. Terranes and continental accretion in the Colombian Andes, Episodes 11: 189-193.

Toussaint, J.F.; Restrepo, J.J. 1988. ¿Son Alóctonos los Andes Colombianos? Universidad Nacional Medellín, Revista Facultad de Ciencias (ICNE) 1: 17-41. Medellín. Valencia, V.A.; Ruiz, J.; Barra, F.; Geherls, G.; Ducea, M.; Titley, S.R.; Ochoa-Landin, L. 2005. U-Pb single zircon and Re-Os geochronology from La Caridad Porphyry Copper Deposit: Insights for the duration of magmatism and mineralization in the Nacozari District, Sonora, Mexico. Mineralium Deposita 40: 175-191.

Van Der Lelij, R. 2013. Reconstructing northwestern Gondwana with implications for the evolution of the Iapetus and Rheic Oceans: a geochronological, thermochronological and geochemical study. Thèse de doctorat. Université Genève: 248 p. Ginebra, Suiza.

Van Der Lelij, R.; Spikings, R.; Ulianov, A.; Chiaradia, M.; Mora, A. 2015. Palaeozoic to Early Jurassic history of the northwestern corner of Gondwana, and implications for the evolution of the Iapetus, Rheic and Pacific Oceans. Gondwana Research 31: 271-294.

Ward, D.; Goldsmith; R.; Cruz, J.; Restrepo, H. 1973. Geología de los Cuadrángulos H-12, Bucaramanga y H-13, Pamplona, Departamento de Santander. Boletín Geológico 21 (1-3): 1-132.

Whitney, D.; Evans, B. 2010. Abbreviations for names of rock-forming minerals. American Mineralogist 95: $185-187$. 
APÉNDICE 1. COMPOSICIÓN QUÍMICA DE LAS ROCAS DEL ORTONEIS.

\begin{tabular}{|c|c|c|c|c|c|}
\hline Contenido & Muestra VR-22-1 & Muestra VR-7-2 & Contenido & Muestra VR-22-1 & Muestra VR-7-2 \\
\hline $\mathrm{SiO}_{2}$ & 76,47 & 72,6 & Co & 2 & 6 \\
\hline $\mathrm{TiO}_{2}$ & 0,1 & 0,48 & Cs & 1,78 & 4,87 \\
\hline $\mathrm{Al}_{2} \mathrm{O}_{3}$ & 12,32 & 12,72 & $\mathrm{Ba}$ & 208 & 453 \\
\hline $\mathrm{Fe}_{2} \mathrm{O}_{3}$ & 2,4 & 2,81 & $\mathrm{Rb}$ & 179 & 170 \\
\hline $\mathrm{MnO}$ & 0,07 & 0,03 & $\mathrm{Sn}$ & 2 & 4 \\
\hline $\mathrm{MgO}$ & 0,17 & 0,77 & Th & 13 & 19,1 \\
\hline $\mathrm{CaO}$ & 1,45 & 1,3 & $\mathrm{Nb}$ & 11,5 & 12,7 \\
\hline $\mathrm{Na}_{2} \mathrm{O}$ & 2,95 & 3,01 & $\mathrm{Ta}$ & 1,4 & 1,1 \\
\hline $\mathrm{K}_{2} \mathrm{O}$ & 3,99 & 4,21 & $\mathrm{Sr}$ & 59,5 & 61,5 \\
\hline $\mathrm{P}_{2} \mathrm{O}_{5}$ & 0,02 & 0,11 & $\mathrm{Zr}$ & 59 & 163 \\
\hline $\mathrm{Cr}_{2} \mathrm{O}_{3}$ & $<0,01$ & $<0,01$ & $\mathrm{Hf}$ & 2,1 & 5,1 \\
\hline $\mathrm{BaO}$ & 0,02 & 0,05 & Y & 21,5 & 42,3 \\
\hline $\mathrm{SrO}$ & 0,01 & 0,01 & $\mathrm{~Pb}$ & 14 & 17 \\
\hline Mo & $<1$ & $<1$ & $\mathrm{U}$ & 2,33 & 2,38 \\
\hline $\mathrm{Ni}$ & $<1$ & 4 & $\mathrm{La}$ & 16 & 32,7 \\
\hline $\mathrm{Zn}$ & 41 & 30 & $\mathrm{Ce}$ & 37,6 & 70,4 \\
\hline $\mathrm{Cu}$ & 2 & 11 & $\operatorname{Pr}$ & 4,17 & 8,34 \\
\hline As & 0,3 & 1 & $\mathrm{Nd}$ & 14,8 & 30,4 \\
\hline $\mathrm{Cd}$ & $<0,5$ & $<0,5$ & $\mathrm{Sm}$ & 3,21 & 6 \\
\hline $\mathrm{Sb}$ & $<0,05$ & $<0,05$ & $\mathrm{Eu}$ & 0,39 & 0,87 \\
\hline $\mathrm{Bi}$ & 0,01 & 0,06 & $\mathrm{Gd}$ & 3,18 & 6,77 \\
\hline $\mathrm{Ag}$ & $<0,5$ & $<0,5$ & $\mathrm{~Tb}$ & 0,53 & 1,12 \\
\hline $\mathrm{Hg}$ & $<0,005$ & $<0,005$ & Dy & 3,39 & 6,99 \\
\hline $\mathrm{Tl}$ & 0,15 & 0,1 & Ho & 0,73 & 1,43 \\
\hline $\mathrm{Se}$ & $<0,2$ & 0,3 & $\mathrm{Er}$ & 2,54 & 4,44 \\
\hline $\mathrm{Ga}$ & 14,8 & 16,6 & $\mathrm{Tm}$ & 0,47 & 0,67 \\
\hline $\mathrm{Sc}$ & 5 & 8 & $\mathrm{Yb}$ & 3,31 & 4,21 \\
\hline V & 19 & 54 & $\mathrm{Lu}$ & 0,54 & 0,65 \\
\hline W & 2 & 1 & - & - & - \\
\hline
\end{tabular}




\begin{tabular}{|c|c|c|c|c|c|c|c|c|c|c|c|c|c|c|c|c|c|c|c|}
\hline \multicolumn{3}{|c|}{$\begin{array}{c}\text { Dept of the Environment, } \\
\text { Washington State } \\
\text { University }\end{array}$} & \multicolumn{9}{|c|}{ Relaciones isotópicas } & \multicolumn{7}{|c|}{ Edades } & \\
\hline \multirow{2}{*}{$\begin{array}{c}\text { Número de } \\
\text { muestra }\end{array}$} & \multirow{2}{*}{$\underset{\mathbf{p p m}}{\mathrm{U}}$} & \multirow{2}{*}{ U/Th } & & \multicolumn{4}{|c|}{$1 \sigma$ Abs Error } & \multirow[b]{2}{*}{${ }^{238} \mathrm{U} /{ }^{206} \mathrm{~Pb}$} & \multirow[b]{2}{*}{$\begin{array}{c}1 \sigma \text { Abs } \\
\text { Error }\end{array}$} & \multirow[b]{2}{*}{${ }^{207} \mathrm{~Pb} /{ }^{206} \mathrm{~Pb}$} & \multirow{2}{*}{$\begin{array}{c}1 \sigma \mathrm{Abs} \\
\text { Error }\end{array}$} & \multicolumn{4}{|c|}{ 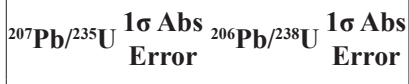 } & \multicolumn{2}{|c|}{${ }^{207} \mathrm{~Pb} /{ }^{206} \mathrm{~Pb} \begin{array}{c}1 \sigma \mathrm{Abs} \\
\text { Error }\end{array}$} & \multirow{2}{*}{$\begin{array}{c}\begin{array}{c}\text { Mejor } \\
\text { edad }\end{array} \\
\text { Ma }\end{array}$} & \multirow{2}{*}{$\begin{array}{r}1 \sigma \mathrm{Ab} \\
\text { Error } \\
\mathrm{Ma}\end{array}$} \\
\hline & & & & $\begin{array}{c}1 \sigma \text { Abs } \\
\text { Error }\end{array}$ & ${ }^{206} \mathrm{~Pb} /{ }^{238} \mathrm{U}$ & Ma & $\begin{array}{l}\text { Corr. } \\
\text { Coef. }\end{array}$ & & & & & Ma & Мa & Мa & Ma & Ma & Ma & & \\
\hline VR-7-2_12 & 1.364 & 1,2 & 0,568 & 0,028 & 0,073 & 0,003 & 0,914 & 13,714 & 0,595 & 0,056 & 0,001 & 456 & 18 & 454 & 9 & 471 & 22 & 454 & 9 \\
\hline VR-7-2_22 & 1.107 & 0,9 & 0,593 & 0,039 & 0,074 & 0,004 & 0,932 & 13,563 & 0,809 & 0,058 & 0,001 & 473 & 25 & 459 & 13 & 544 & 26 & 459 & 13 \\
\hline VR-7-2_13 & 1.456 & 1,2 & 0,580 & 0,028 & 0,074 & 0,003 & 0,926 & 13,478 & 0,576 & 0,057 & 0,001 & 464 & 18 & 461 & 10 & 480 & 20 & 461 & 10 \\
\hline VR-7-2_11 & 1.595 & 0,7 & 0,588 & 0,028 & 0,075 & 0,003 & 0,931 & 13,381 & 0,572 & 0,057 & 0,001 & 469 & 18 & 465 & 10 & 493 & 19 & 465 & 10 \\
\hline VR-7-2_10 & 1.475 & 1,1 & 0,598 & 0,028 & 0,076 & 0,003 & 0,924 & 13,231 & 0,548 & 0,057 & 0,001 & 476 & 18 & 470 & 9 & 507 & 20 & 470 & 9 \\
\hline VR-7-2_36 & 1.303 & 0,6 & 0,600 & 0,030 & 0,076 & 0,003 & 0,916 & 13,192 & 0,565 & 0,057 & 0,001 & 477 & 19 & 471 & 10 & 509 & 22 & 471 & 10 \\
\hline VR-7-2_25 & 1.138 & 1,2 & 0,612 & 0,030 & 0,076 & 0,003 & 0,924 & 13,116 & 0,573 & 0,058 & 0,001 & 485 & 19 & 474 & 10 & 540 & 21 & 474 & 10 \\
\hline VR-7-2_44 & 1.417 & 0,8 & 0,591 & 0,035 & 0,076 & 0,004 & 0,937 & 13,081 & 0,698 & 0,056 & 0,001 & 471 & 22 & 475 & 12 & 455 & 23 & 475 & 12 \\
\hline VR-7-2_9 & 1.781 & 0,4 & 0,609 & 0,029 & 0,077 & 0,003 & 0,926 & 13,061 & 0,545 & 0,058 & 0,001 & 483 & 18 & 476 & 10 & 517 & 20 & 476 & 10 \\
\hline VR-7-2_17 & 1.740 & 0,3 & 0,605 & 0,029 & 0,077 & 0,003 & 0,932 & 13,041 & 0,549 & 0,057 & 0,001 & 481 & 18 & 476 & 10 & 502 & 19 & 476 & 10 \\
\hline VR-7-2_40 & 1.468 & 0,3 & 0,591 & 0,030 & 0,077 & 0,003 & 0,927 & 12,962 & 0,586 & 0,056 & 0,001 & 472 & 19 & 479 & 10 & 437 & 21 & 479 & 10 \\
\hline VR-7-2_45 & 1.527 & 0,7 & 0,620 & 0,043 & 0,077 & 0,005 & 0,940 & 12,943 & 0,830 & 0,058 & 0,001 & 490 & 27 & 480 & 15 & 537 & 26 & 480 & 15 \\
\hline VR-7-2_27 & 566 & 1,5 & 0,599 & 0,031 & 0,077 & 0,003 & 0,891 & 12,918 & 0,568 & 0,056 & 0,001 & 476 & 20 & 481 & 10 & 457 & 26 & 481 & 10 \\
\hline VR-7-2_38 & 740 & 1,0 & 0,646 & 0,035 & 0,077 & 0,004 & 0,908 & 12,918 & 0,599 & 0,061 & 0,001 & 506 & 21 & 481 & 11 & 623 & 24 & 481 & 11 \\
\hline VR-7-2_51 & 3.581 & 0,2 & 0,607 & 0,034 & 0,078 & 0,004 & 0,952 & 12,899 & 0,654 & 0,057 & 0,001 & 481 & 21 & 481 & 12 & 482 & 19 & 481 & 12 \\
\hline VR-7-2_37 & 1.917 & 0,3 & 0,635 & 0,031 & 0,078 & 0,003 & 0,930 & 12,885 & 0,552 & 0,059 & 0,001 & 499 & 19 & 482 & 10 & 580 & 19 & 482 & 10 \\
\hline VR-7-2_26 & 810 & 1,7 & 0,618 & 0,031 & 0,078 & 0,003 & 0,908 & 12,859 & 0,557 & 0,058 & 0,001 & 489 & 19 & 483 & 10 & 516 & 23 & 483 & 10 \\
\hline VR-7-2_39 & 694 & 0,9 & 0,631 & 0,033 & 0,078 & 0,004 & 0,908 & 12,830 & 0,580 & 0,059 & 0,001 & 497 & 20 & 484 & 11 & 559 & 24 & 484 & 11 \\
\hline VR-7-2_50 & 755 & 0,4 & 0,630 & 0,041 & 0,079 & 0,005 & 0,916 & 12,645 & 0,722 & 0,058 & 0,001 & 496 & 25 & 491 & 13 & 523 & 28 & 491 & 13 \\
\hline VR-7-2_52 & 1.371 & 0,2 & 0,624 & 0,035 & 0,080 & 0,004 & 0,929 & 12,559 & 0,635 & 0,057 & 0,001 & 492 & 22 & 494 & 12 & 487 & 23 & 494 & 12 \\
\hline VR-7-2_23 & 426 & 1,1 & 0,618 & 0,045 & 0,080 & 0,005 & 0,928 & 12,539 & 0,831 & 0,056 & 0,002 & 489 & 28 & 495 & 16 & 462 & 30 & 495 & 16 \\
\hline VR-7-2_53 & 2.843 & 0,3 & 0,634 & 0,032 & 0,082 & 0,004 & 0,940 & 12,126 & 0,558 & 0,056 & 0,001 & 499 & 20 & 511 & 11 & 445 & 19 & 511 & 11 \\
\hline VR-7-2_41 & 1.122 & 0,5 & 0,792 & 0,042 & 0,083 & 0,004 & 0,899 & 12,027 & 0,551 & 0,069 & 0,002 & 592 & 24 & 515 & 11 & 901 & 24 & 515 & 11 \\
\hline VR-7-2_33 & 600 & 0,7 & 0,815 & 0,046 & 0,088 & 0,004 & 0,882 & 11,386 & 0,536 & 0,067 & 0,002 & 605 & 25 & 543 & 12 & 849 & 27 & 543 & 12 \\
\hline VR-7-2_15 & 1.113 & 0,3 & 0,765 & 0,038 & 0,090 & 0,004 & 0,931 & 11,159 & 0,494 & 0,062 & 0,001 & 577 & 22 & 553 & 12 & 671 & 20 & 553 & 12 \\
\hline VR-7-2_47 & 2.027 & 0,1 & 1,020 & 0,062 & 0,112 & 0,006 & 0,950 & 8,958 & 0,501 & 0,066 & 0,001 & 714 & 31 & 682 & 18 & 815 & 20 & 682 & 18 \\
\hline
\end{tabular}




\begin{tabular}{|c|c|c|c|c|c|c|c|c|c|c|c|c|c|c|c|c|c|c|c|}
\hline \multicolumn{3}{|c|}{$\begin{array}{l}\text { Dept of the Environment, } \\
\text { Washington State } \\
\text { University }\end{array}$} & \multicolumn{9}{|c|}{ Relaciones isotópicas } & \multicolumn{6}{|c|}{ Edades } & & \\
\hline \multirow{2}{*}{$\begin{array}{l}\text { Número de } \\
\text { muestra }\end{array}$} & \multirow{2}{*}{$\begin{array}{c}\mathrm{U} \\
\mathrm{ppm}\end{array}$} & \multirow{2}{*}{$\mathbf{U} / \mathbf{T h}$} & \multicolumn{5}{|c|}{$1 \sigma$ Abs Error } & \multirow[b]{2}{*}{${ }^{238} \mathbf{U} /{ }^{206} \mathbf{P b}$} & \multirow[b]{2}{*}{$\begin{array}{l}1 \sigma \text { Abs } \\
\text { Error }\end{array}$} & \multirow[b]{2}{*}{${ }^{207} \mathrm{~Pb} /{ }^{206} \mathrm{~Pb}$} & \multirow[b]{2}{*}{$\begin{array}{c}1 \sigma \text { Abs } \\
\text { Error }\end{array}$} & \multicolumn{6}{|c|}{ 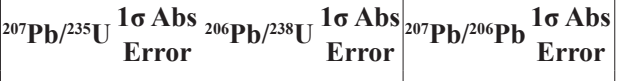 } & \multirow{2}{*}{$\begin{array}{c}\text { Mejor } \\
\text { edad } \\
\text { Ma }\end{array}$} & \multirow{2}{*}{$\begin{array}{c}1 \sigma \text { Abs } \\
\text { Error } \\
\text { Ma }\end{array}$} \\
\hline & & & ${ }^{207} \mathbf{P b} /{ }^{235} \mathrm{U}$ & $\begin{array}{l}1 \sigma \text { Abs } \\
\text { Error }\end{array}$ & ${ }^{206} \mathrm{~Pb} /{ }^{238} \mathrm{U}$ & Ма & $\begin{array}{l}\text { Corr. } \\
\text { Coef. }\end{array}$ & & & & & Мa & Ма & Мa & Ма & Ма & Мa & & \\
\hline VR-7-2_48 & 609 & 1,2 & 1,396 & 0,086 & 0,145 & 0,008 & 0,948 & 6,874 & 0,390 & 0,070 & 0,001 & 887 & 36 & 876 & 23 & 917 & 20 & 876 & 23 \\
\hline VR-7-2_46 & 1.034 & 0,1 & 1,525 & 0,093 & 0,157 & 0,009 & 0,941 & 6,360 & 0,353 & 0,070 & 0,001 & 940 & 37 & 941 & 24 & 939 & 21 & 941 & 24 \\
\hline VR-7-2_8 & 603 & 0,6 & 1,416 & 0,069 & 0,144 & 0,006 & 0,929 & 6,937 & 0,296 & 0,071 & 0,001 & 896 & 29 & 868 & 17 & 965 & 18 & 868 & 17 \\
\hline VR-7-2_16 & 313 & 0,8 & 1,488 & 0,075 & 0,151 & 0,007 & 0,904 & 6,623 & 0,285 & 0,071 & 0,002 & 925 & 30 & 907 & 18 & 972 & 22 & 907 & 18 \\
\hline VR-7-2_21 & 697 & 0,6 & 1,718 & 0,107 & 0,173 & 0,010 & 0,951 & 5,789 & 0,334 & 0,072 & 0,001 & 1.015 & 40 & 1.027 & 27 & 990 & 20 & 990 & 27 \\
\hline VR-7-2_20 & 750 & 0,6 & 1,684 & 0,102 & 0,169 & 0,009 & 0,950 & 5,932 & 0,330 & 0,072 & 0,001 & 1.003 & 38 & 1.004 & 26 & 1.000 & 19 & 1.000 & 19 \\
\hline VR-7-2_35 & 1.118 & 0,2 & 1,324 & 0,079 & 0,125 & 0,007 & 0,926 & 7,997 & 0,429 & 0,077 & 0,002 & 856 & 34 & 760 & 19 & 1.116 & 22 & 760 & 19 \\
\hline VR-7-2_28 & 137 & 0,8 & 2,081 & 0,113 & 0,191 & 0,009 & 0,881 & 5,224 & 0,238 & 0,079 & 0,002 & 1.143 & 37 & 1.129 & 24 & 1.169 & 25 & 1.169 & 25 \\
\hline VR-7-2_34 & 2.223 & 0,1 & 3,242 & 0,155 & 0,252 & 0,011 & 0,952 & 3,961 & 0,172 & 0,093 & 0,001 & 1.467 & 37 & 1.451 & 28 & 1.491 & 14 & 1.491 & 14 \\
\hline VR-7-2_29 & 841 & 0,8 & 3,423 & 0,160 & 0,255 & 0,011 & 0,946 & 3,915 & 0,164 & 0,097 & 0,001 & 1.510 & 36 & 1.466 & 27 & 1.572 & 14 & 1.572 & 14 \\
\hline VR-7-2_32 & 411 & 0,8 & 3,404 & 0,173 & 0,239 & 0,011 & 0,946 & 4,180 & 0,192 & 0,103 & 0,002 & 1.505 & 39 & 1.383 & 28 & 1.683 & 15 & 1.683 & 15 \\
\hline VR-22-1_17 & 920 & 0,4 & 0,446 & 0,023 & 0,057 & 0,002 & 0,911 & 17,581 & 0,751 & 0,057 & 0,001 & 375 & 16 & 357 & 7 & 489 & 23 & 357 & 7 \\
\hline VR-22-1_9 & 8.243 & 0,3 & 0,478 & 0,024 & 0,063 & 0,003 & 0,942 & 15,972 & 0,691 & 0,055 & 0,001 & 397 & 16 & 391 & 8 & 428 & 19 & 391 & 8 \\
\hline VR-22-1_31 & 4.995 & 0,4 & 0,513 & 0,025 & 0,064 & 0,003 & 0,935 & 15,688 & 0,666 & 0,058 & 0,001 & 421 & 17 & 398 & 8 & 546 & 19 & 398 & 8 \\
\hline VR-22-1_13 & 5.236 & 0,2 & 0,549 & 0,027 & 0,069 & 0,003 & 0,936 & 14,579 & 0,618 & 0,058 & 0,001 & 444 & 17 & 428 & 9 & 532 & 19 & 428 & 9 \\
\hline VR-22-1_12 & 2.652 & 0,3 & 0,553 & 0,028 & 0,071 & 0,003 & 0,940 & 14,021 & 0,633 & 0,056 & 0,001 & 447 & 18 & 444 & 10 & 462 & 20 & 444 & 10 \\
\hline VR-22-1_47 & 472 & 0,6 & 0,585 & 0,031 & 0,073 & 0,003 & 0,892 & 13,642 & 0,594 & 0,058 & 0,001 & 468 & 20 & 456 & 10 & 526 & 26 & 456 & 10 \\
\hline VR-22-1_10 & 3.537 & 0,3 & 0,585 & 0,028 & 0,074 & 0,003 & 0,944 & 13,527 & 0,567 & 0,057 & 0,001 & 468 & 18 & 460 & 9 & 507 & 18 & 460 & 9 \\
\hline VR-22-1_22 & 1.295 & 0,8 & 0,580 & 0,029 & 0,074 & 0,003 & 0,922 & 13,500 & 0,586 & 0,057 & 0,001 & 464 & 19 & 461 & 10 & 482 & 22 & 461 & 10 \\
\hline VR-22-1_41 & 7.436 & 0,3 & 0,576 & 0,029 & 0,074 & 0,003 & 0,945 & 13,479 & 0,603 & 0,056 & 0,001 & 462 & 19 & 461 & 10 & 467 & 19 & 461 & 10 \\
\hline VR-22-1_50 & 819 & 0,7 & 0,583 & 0,032 & 0,074 & 0,003 & 0,908 & 13,460 & 0,624 & 0,057 & 0,001 & 466 & 20 & 462 & 10 & 489 & 25 & 462 & 10 \\
\hline VR-22-1_49 & 1.828 & 0,5 & 0,585 & 0,032 & 0,074 & 0,004 & 0,944 & 13,440 & 0,656 & 0,057 & 0,001 & 468 & 20 & 463 & 11 & 492 & 20 & 463 & 11 \\
\hline VR-22-1_42 & 920 & 0,4 & 0,582 & 0,030 & 0,075 & 0,003 & 0,927 & 13,391 & 0,592 & 0,057 & 0,001 & 466 & 19 & 464 & 10 & 475 & 21 & 464 & 10 \\
\hline VR-22-1_25 & 2.923 & 0,5 & 0,594 & 0,031 & 0,075 & 0,003 & 0,937 & 13,349 & 0,612 & 0,057 & 0,001 & 473 & 20 & 466 & 10 & 510 & 20 & 466 & 10 \\
\hline VR-22-1_48 & 1.704 & 0,6 & 0,587 & 0,030 & 0,075 & 0,003 & 0,939 & 13,338 & 0,591 & 0,057 & 0,001 & 469 & 19 & 466 & 10 & 483 & 19 & 466 & 10 \\
\hline VR-22-1_43 & 1.667 & 0,6 & 0,588 & 0,028 & 0,075 & 0,003 & 0,936 & 13,253 & 0,557 & 0,056 & 0,001 & 469 & 18 & 469 & 9 & 472 & 19 & 469 & 9 \\
\hline VR-22-1_19 & 692 & 0,7 & 0,594 & 0,030 & 0,076 & 0,003 & 0,907 & 13,227 & 0,566 & 0,057 & 0,001 & 473 & 19 & 470 & 10 & 490 & 24 & 470 & 10 \\
\hline VR-22-1_18 & 470 & 1,1 & 0,590 & 0,030 & 0,076 & 0,003 & 0,902 & 13,204 & 0,554 & 0,056 & 0,001 & 471 & 19 & 471 & 10 & 471 & 24 & 471 & 10 \\
\hline VR-22-1_23 & 1.149 & 1,0 & 0,594 & 0,030 & 0,076 & 0,003 & 0,912 & 13,165 & 0,554 & 0,057 & 0,001 & 474 & 19 & 472 & 10 & 482 & 23 & 472 & 10 \\
\hline
\end{tabular}




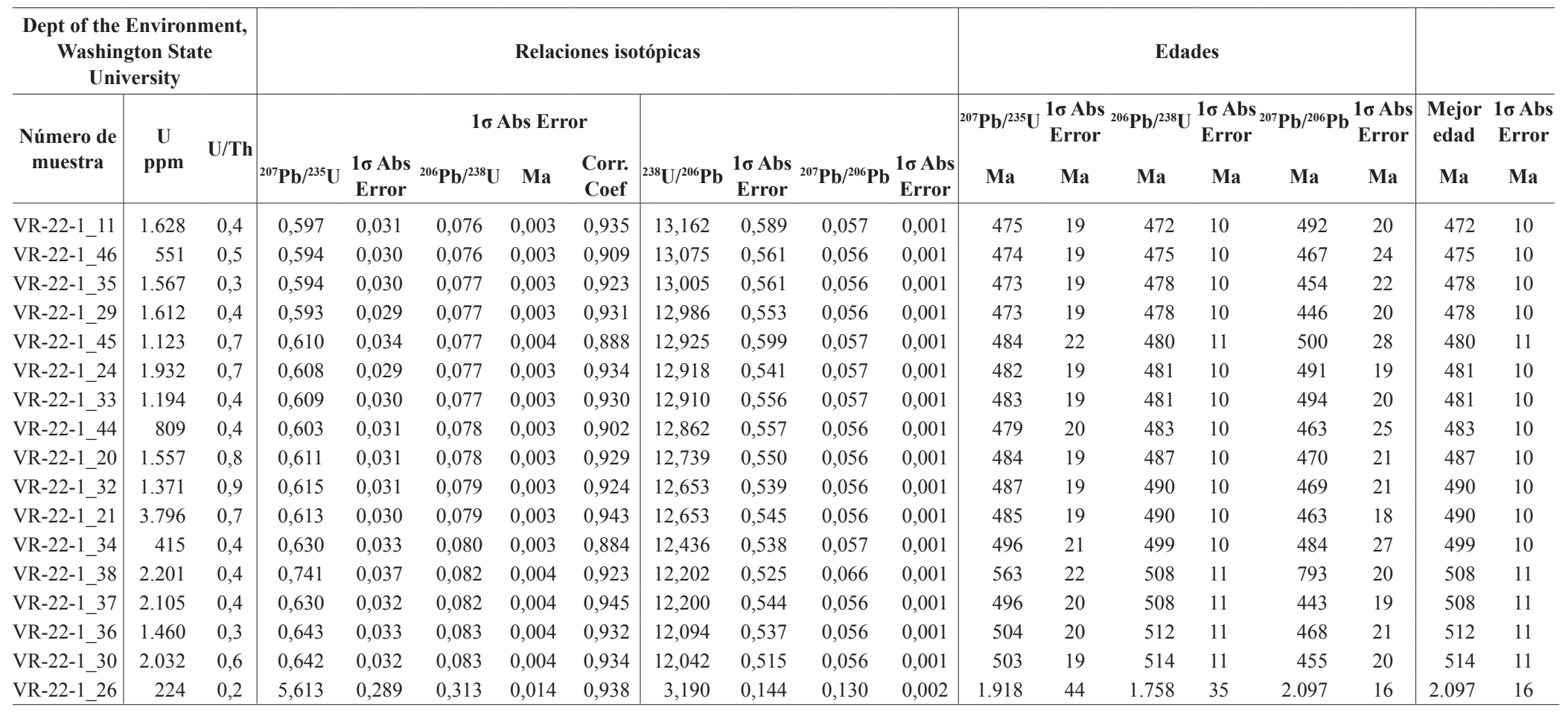

$\mathrm{U}$ concentration uncertainty is $\sim 20 \%$

Data not corrected for common-pb.

Individual errors are given as 1 sigma standard deviation and only reflect the internal error, systematic errors are ${ }^{206} \mathrm{~Pb} /{ }^{238} \mathrm{U}=1.9 \%,{ }^{207} \mathrm{~Pb} /{ }^{206} \mathrm{~Pb}=0.9 \%$. 